\title{
Les caves gallo-romaines dans les campagnes de
}

\section{Haute-Normandie}

Roman Cellars in Upper Normandy Country

Die gallo-römischen Keller in den ländlichen Siedlungen der Haute-Normandie

Las cuevas galo-romanas en los campos de Haute-Normandie

Yves-Marie Adrian, Claire Beurion, Dagmar Lukas et Serge Le Maho

\section{(2) OpenEdition}

\section{Journals}

Édition électronique

URL : http://journals.openedition.org/rao/2710

DOI : $10.4000 /$ rao. 2710

ISBN : 978-2-7535-4053-8

ISSN : 1775-3732

Éditeur

Presses universitaires de Rennes

Édition imprimée

Date de publication : 15 décembre 2014

Pagination : 369-402

ISBN : 978-2-7535-4051-4

ISSN : 0767-709X

\section{Référence électronique}

Yves-Marie Adrian, Claire Beurion, Dagmar Lukas et Serge Le Maho, « Les caves gallo-romaines dans les campagnes de Haute-Normandie », Revue archéologique de l'Ouest [En ligne], 31 | 2014, mis en ligne le 15 décembre 2016, consulté le 03 décembre 2020. URL : http://journals.openedition.org/rao/2710 ; DOI : https://doi.org/10.4000/rao.2710 


\title{
Les caves gallo-romaines dans les campagnes de Haute-Normandie

\author{
Roman Cellars in Upper Normandy
}

\author{
Yves-Marie Adrian*, Claire Beurion* et Dagmar Lukas* \\ avec la collaboration de Serge Le Maнo*
}

\begin{abstract}
Résumé : La fouille récente de quatre caves antiques en Haute-Normandie offre l'opportunité d'une approche conjointe et comparative de ces pièces enterrées. À travers leur variété architecturale ainsi que leurs différents emplacements, ces caves livrent bon nombre d'informations sur les choix des commanditaires comme des constructeurs. Au-delà, c'est bien évidemment la question de leurs fonctions qui peut être approchée, même si celles-ci restent difficiles à préciser, faute d'indices. Leurs comblements s'avèrent également souvent précieux pour la caractérisation des occupations qui leur sont associées.
\end{abstract}

\begin{abstract}
The recent excavation of four Roman cellars in Upper Normandy has provided the opportunity of a combined and comparative study of the structures. Through the diversity of their architecture and their different locations, the cellars provide information on the choices made by the owners as well as by the builders. Also, the question of their use will also be broached even if there is little evidence. Their fill has proved to be informative as to the characterisation of the settlements to with they are associated.
\end{abstract}

Mots clés : cave, Antiquité, Haute-Normandie, milieu rural, architecture.

Keywords: Cellar, Roman, Upper Normandy, rural context, architecture.

\section{INTRODUCTION}

Les caves font partie des aménagements presque emblématiques des sites gallo-romains urbains et ruraux tandis que leur nombre, agencement et emplacement constituent autant d'éléments décisifs pour la connaissance des sites, régulièrement augmentée par le volume et la qualité du mobilier qu'elles peuvent contenir dans leur comblement. Mais alors qu'elles sont particulièrement répandues dans l'habitat urbain, les caves sont beaucoup moins présentes dans les campagnes. Ce phénomène est toutefois plus ou moins marqué d'un territoire à l'autre et si certaines régions en sont abondamment pourvues, d'autres en sont nettement moins dotées, sans que les raisons soient aujourd'hui clairement identifiées. C'est notamment le cas de la HauteNormandie où le nombre de caves reste peu important malgré la fouille de nombreux établissements depuis une vingtaine d'années. Quelques découvertes plus anciennes alimentent un maigre corpus mais la plupart sont mal documentées, en particulier en ce qui concerne leur mode de construction et leur environnement immédiat.

Quatre caves haut-normandes exhumées en milieu rural entre 2006 et 2012 (fig. 1) offrent des éléments de réflexion sur ces constructions enterrées, en termes d'emplacement ou d'architecture, comme de fonction. Les données relatives à ces caves sont variées et pour certaines convergentes, notamment du point de vue topographique et chronologique. Ce dernier aspect n'est pas des moindres puisque trois d'entre elles sont abandonnées à peu près à la même période alors que leur construction reste souvent mal datée, faute de données chronologiques directes.

* Institut national de recherches archéologiques préventives (Inrap Grand Ouest). (yves-marie.adrian@inrap.fr) 


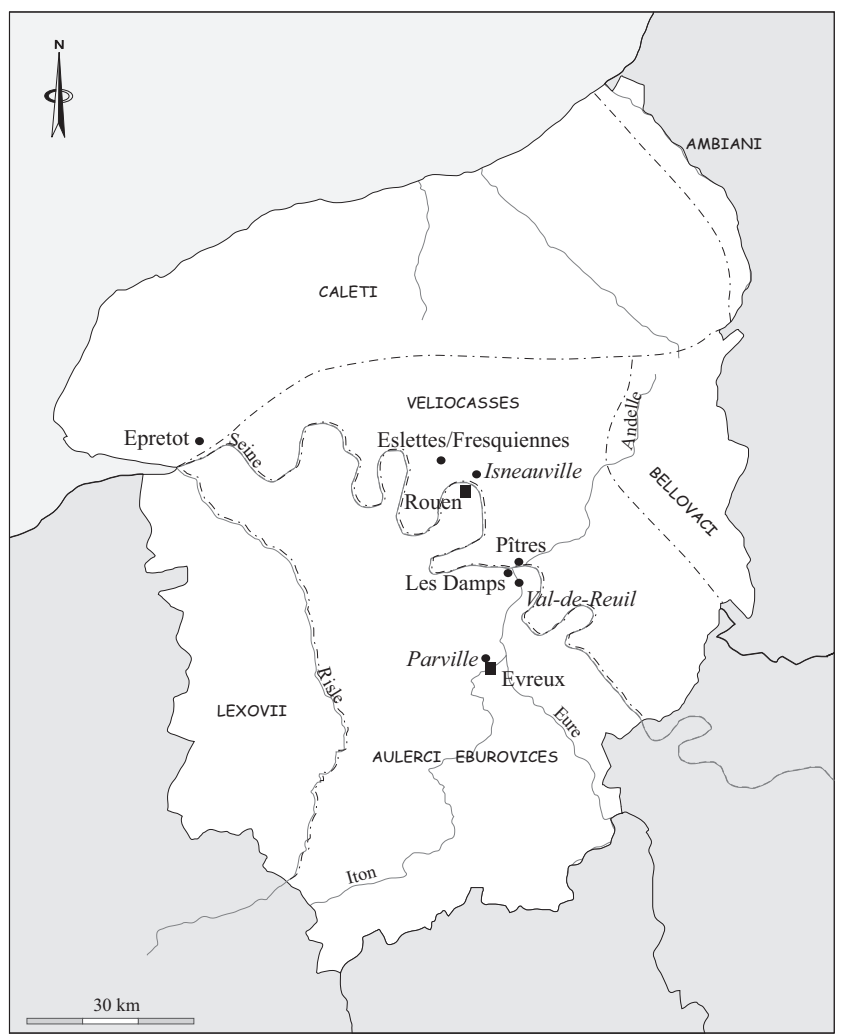

Figure 1 : Localisation régionale des sites concernés (en italique) et mentionnés.

Figure 1 : Regional map of the sites mentioned in the paper.

\section{Caves ou Celliers : UN POINT DE VOCABULAIRE}

Si les dictionnaires différencient une cave d'un cellier, deux espaces destinés au stockage, par leur caractère enterré ou non, la littérature archéologique utilise indifféremment les deux termes pour des structures ou constructions toujours enterrées, tout en introduisant régulièrement une hiérarchie. Ainsi, le terme cellier est, pour l'époque antique, souvent réservé à une petite construction ${ }^{1}$ habillée de bois ou de pierre sèche mais rarement maçonnée au mortier, et dans laquelle un accès spécifique n'existe pas toujours, montrant alors que l'on y accédait par une échelle. L'existence d'un espace de circulation au fond n'est d'ailleurs pas toujours manifeste, ne serait-ce qu'en raison de la superficie restreinte qui rend impossible toute occupation proprement dite. Par ailleurs, la question de l'élévation du cellier et de sa couverture, sous quelque forme que ce soit, ne peut être que très rarement abordée, faute d'indices, notamment devant la légèreté de l'ensemble.

1. Alors que les celliers sont au contraire des pièces souvent vastes dans la terminologie médiévale.
La cave est quant à elle souvent considérée comme une véritable pièce de plusieurs mètres carrés accessible par un escalier et offrant un espace de circulation. Son mode de construction peut varier mais apparaît systématiquement pérenne (construction en pierre ou plus rarement en pierre et terre cuite architecturale, voire en bois) tandis qu'il est associé à une superstructure ménageant une pièce en rez-dechaussée, couverte d'une toiture.

Si l'on retient cette distinction qui a bien entendu ses limites, notamment en fonction des périodes, les constructions présentées appartiennent clairement à la seconde catégorie de pièces souterraines. Celles-ci s'avèrent particulièrement variées, tout comme leur emplacement et sans doute aussi leur rôle au sein des sites concernés.

\section{LES SITES}

Les quatre établissements antiques sont répartis en différents secteurs de la Haute-Normandie, implantés sur les plateaux ou dans une vallée. Tous correspondent à des occupations rurales largement étudiées à la faveur de grands décapages et pour lesquelles le terme de villa ne semble pas toujours approprié, notamment au regard de leur morphologie et de leur envergure. Par ailleurs, leur emplacement differe : deux implantations se trouvent à proximité immédiate des chefs-lieux de cité Rouen et Évreux tandis que les deux autres apparaissent plutôt en limite des cités des Veliocasses et des Aulerques Eburovices (fig. 1).

Le premier se trouve à Parville, Le Bois de Parville (Eure), en périphérie d'Évreux (Mediolanum Aulercorum) et à proximité de la voie reliant cette capitale de cité à Noviomagus (Lisieux), chef-lieu de cité des Lexovii. Installé en rebord de plateau, ce site fouillé sur environ trois hectares a révélé les vestiges d'un domaine qui se développe entre le $\mathrm{I}^{\mathrm{er}}$ et le $\mathrm{IV}^{\mathrm{e}}$ siècle (Lukas, Lecler-Huby, 2010). Celui-ci connaît un développement significatif à partir de l'époque flavienne et prospère jusqu'au milieu du III $^{e}$ siècle, avant une réoccupation sous une forme différente jusqu'à la seconde moitié du IV siècle. L'établissement du Haut-Empire s'articule autour de quatre constructions à fondations en pierre, dont une est dotée d'un hypocauste, ainsi que de différentes structures en creux relatives à de multiples activités domestiques, agricoles (dont un pressoir vinicole) ou artisanales. La cave se trouve dans le secteur bâti qui regroupe plusieurs petites constructions en pierre et en bois constituant le noyau du domaine (fig. 2 et 3).

Le deuxième site dont il est question a été découvert à Isneauville (Seine-Maritime), sur le plateau se développant au nord de Rouen, chef-lieu de cité des Veliocasses (Adrian, [dir.], 2011). L'étendue de la fouille, couvrant environ quatre 


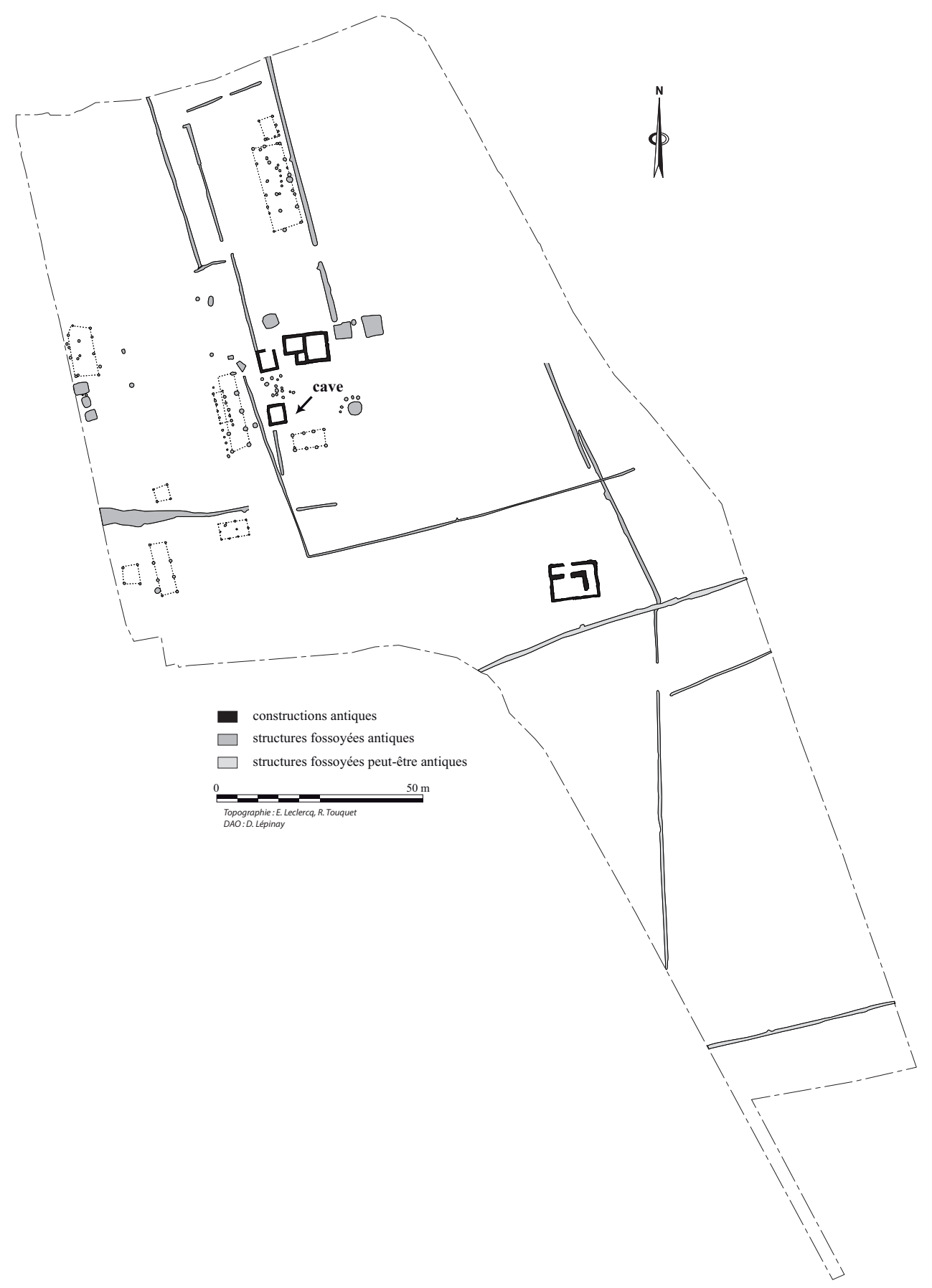

Figure 2 : Extrait du plan de l'occupation antique de Parville avec localisation de la cave.

Figure 2 : Extract of the excavation plan of the Roman settlement of Parville with the location of the cellar. 


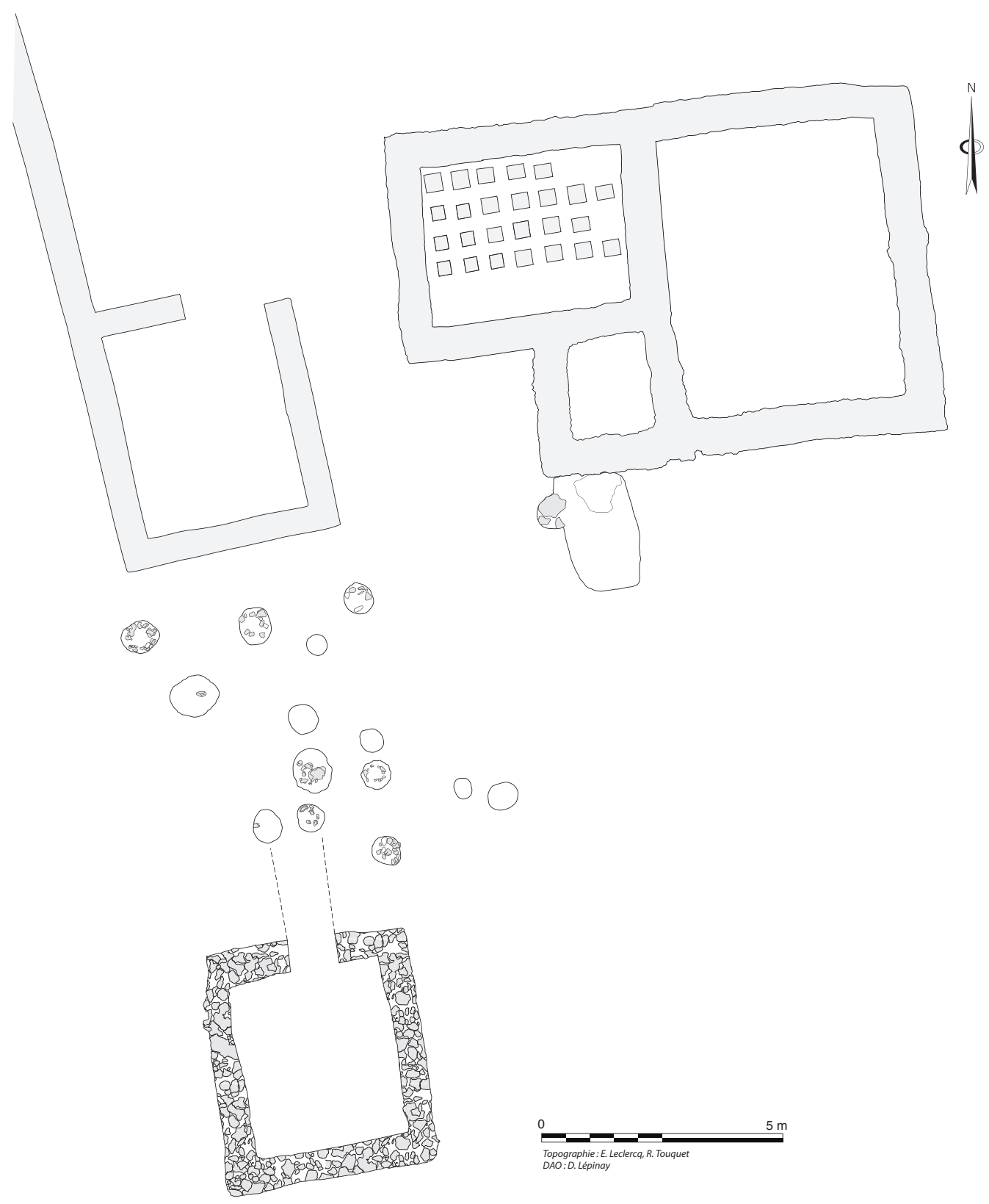

Figure 3 : Emplacement de la cave de Parville au sein de la zone de bâti antique. Figure 3 : Location of the cellar at Parville within the Roman buildings.

hectares, offre une vision large de l'exploitation agricole dont la forme et l'évolution depuis La Tène moyenne évoquent plus une simple ferme de tradition indigène qu'une villa, et ce malgré la présence de plusieurs bâtiments construits sur fondations en pierre (fig. 4). Sa chronologie couvre tout le
Haut-Empire, suivie d'une réoccupation au IV siècle. Tout comme à Parville, la cave fait partie du noyau bâti principal composé d'un bâtiment résidentiel et d'un grenier sur fondations. En revanche, sa construction est associée à l'agrandissement du bâtiment d'habitation, par l'adjonction sur 


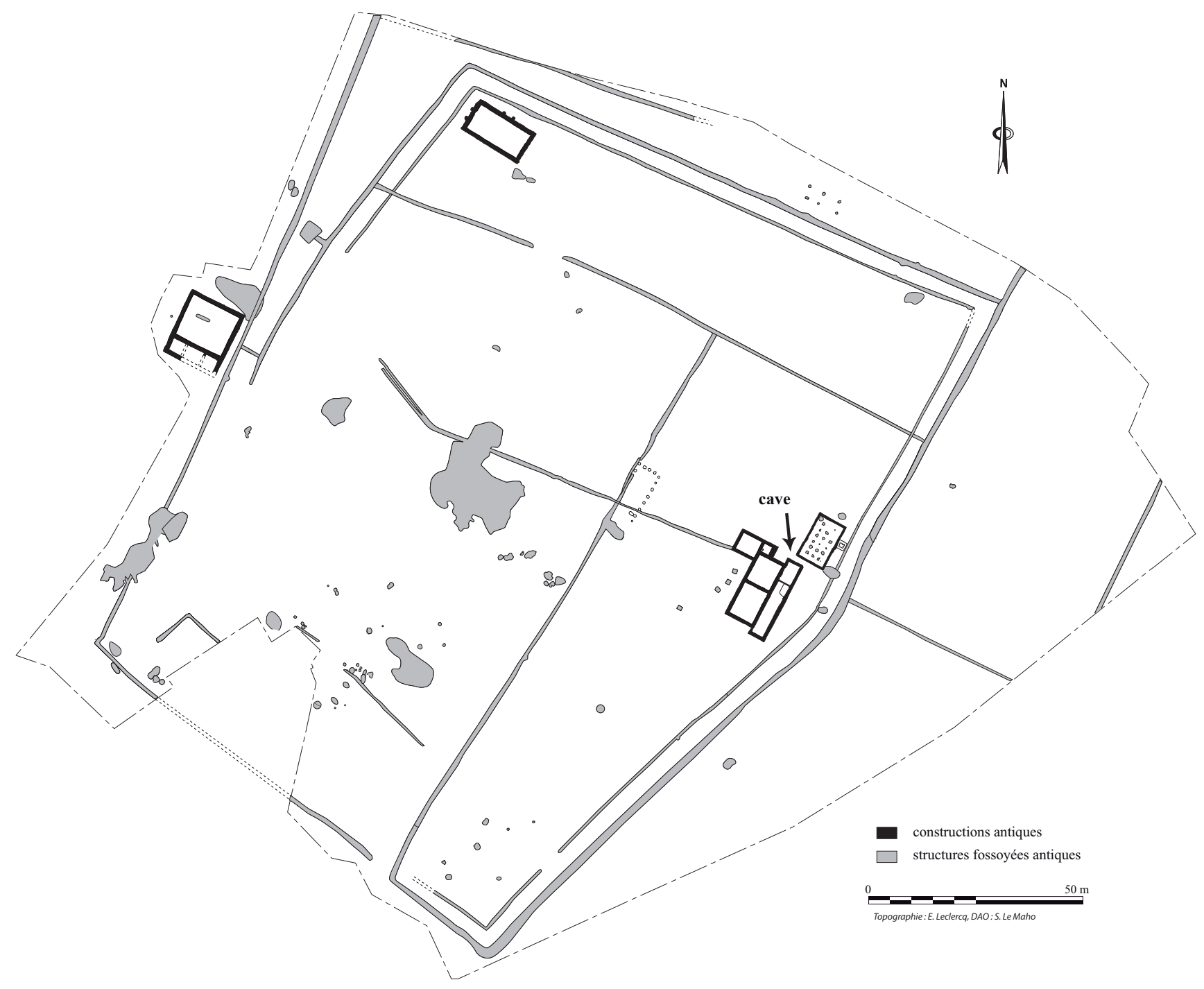

Figure 4 : Plan général de l'occupation antique d'Isneauville et localisation du bâtiment résidentiel avec sa cave. Figure 4 : General plan of the Roman site of Isneauville and location of the residential building and cellar.

sa façade arrière d'une pièce longue mais étroite au sein de laquelle la cave est intégrée (fig. 5).

Les deux autres sites concernés se trouvent sur le territoire communal de Val-de-Reuil (Eure), non loin de la confluence Seine-Eure. L'un est implanté au sud de la ville actuelle, au lieu-dit La Cerisaie, sur la haute terrasse alluviale de l'Eure (30-35 mètres NGF) et s'intègre dans un terroir agricole reconnu sur une trentaine d'hectares, dont l'origine remonte à La Tène finale (Beurion [dir.], 2012). Le réseau parcellaire antique accueille quelques petites unités d'exploitation isolées dont la plus remarquable est celle de La Cerisaie. Cette implantation gallo-romaine (fin $\mathrm{I}^{\mathrm{er}}-\mathrm{III}^{\mathrm{e}}$ siècle), très circons- crite dans un angle de parcelle, se compose d'un unique bâtiment sur cave et d'un profond puits à eau (fig. 6).

Le second site étudié à Val-de-Reuil se trouve quant à lui dans la partie septentrionale de la commune, au bord de l'Eure et à faible distance de la Seine, au lieu-dit Les Errants (Adrian, 2011-2012, étude en cours). Les vestiges antiques correspondent cette fois à une vaste villa délimitée par une enceinte couvrant au moins 15600 mètres carrés au sein desquels s'articulent plusieurs bâtiments édifiés au $\mathrm{II}^{\mathrm{e}}$ siècle (fig. 7). La cave y représente l'un des aménagements les plus anciens puisqu'elle est construite puis abandonnée au $1^{\text {er }}$ siècle. 


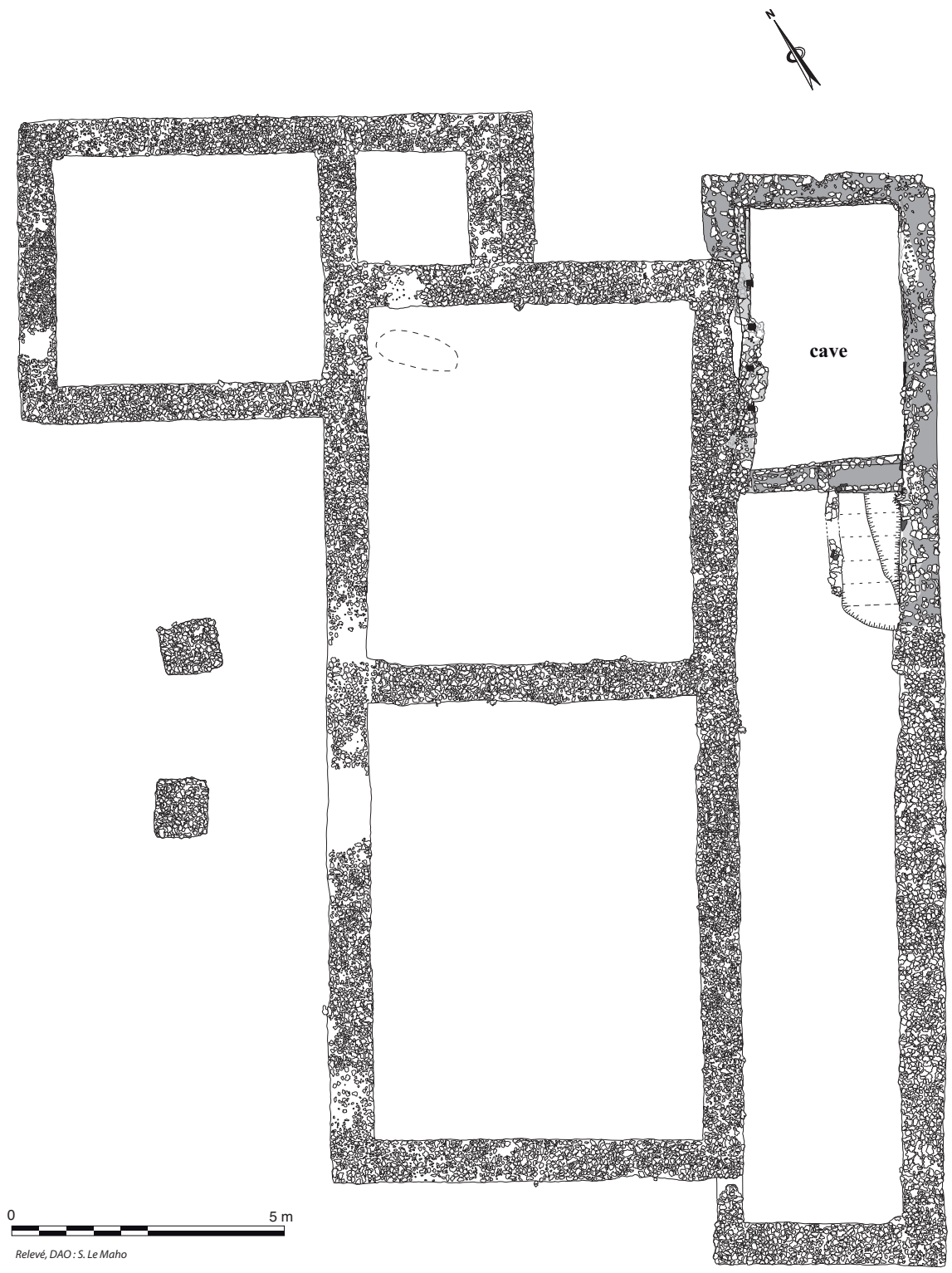

Figure 5 : Le bâtiment résidentiel d'Isneauville avec sa cave.

Figure 5: The residential building at Isneauville and its cellar.

\section{Description des CaVes}

\section{La cave de Parville}

Elle mesure $5 \times 4,50$ mètres en dimensions extérieures et 3,70 x 3,20 mètres en dimensions intérieures, pour une superficie utile de presque 12 mètres carrés et un volume de stockage supérieur à 24 mètres cubes (fig. 8 à 10). Ses murs, conservés sur une hauteur de deux mètres, soit quinze assises de pierres, s'appuient contre les parois du terrain naturel composé d'argiles à silex. Larges de 0,60 à 0,70 mètre dans le tiers supérieur, ils ne dépassent pas 0,50 mètre à leur base. Les maçonneries sont composées de rognons de silex plus ou moins assisés et parementés à l'intérieur (fig. 11). Des moellons calcaires forment les chaînages d'angle, les piédroits ouest et est de la porte d'accès et l'encadrement de deux soupiraux ou niches. Les moellons calcaires marquent une hauteur d'assises plus ou moins régulière d'une dizaine de centimètres. Leurs longueur et largeur suivent toutefois des gabarits variables (long. 20 à $40 \mathrm{~cm}$; larg. 10 à $15 \mathrm{~cm}$ ). Ces moellons ont été aplanis sur trois faces (lits de pose et d'attente et face apparente), tandis que l'arrière est resté quasiment brut d'extraction. Des traces de taille en arêtes de poisson, réalisées au marteau taillant, couvrent leur face apparente (fig. 11 et 12). Ce parement en silex et calcaire constitue un coffrage pour un blocage grossier composé de 


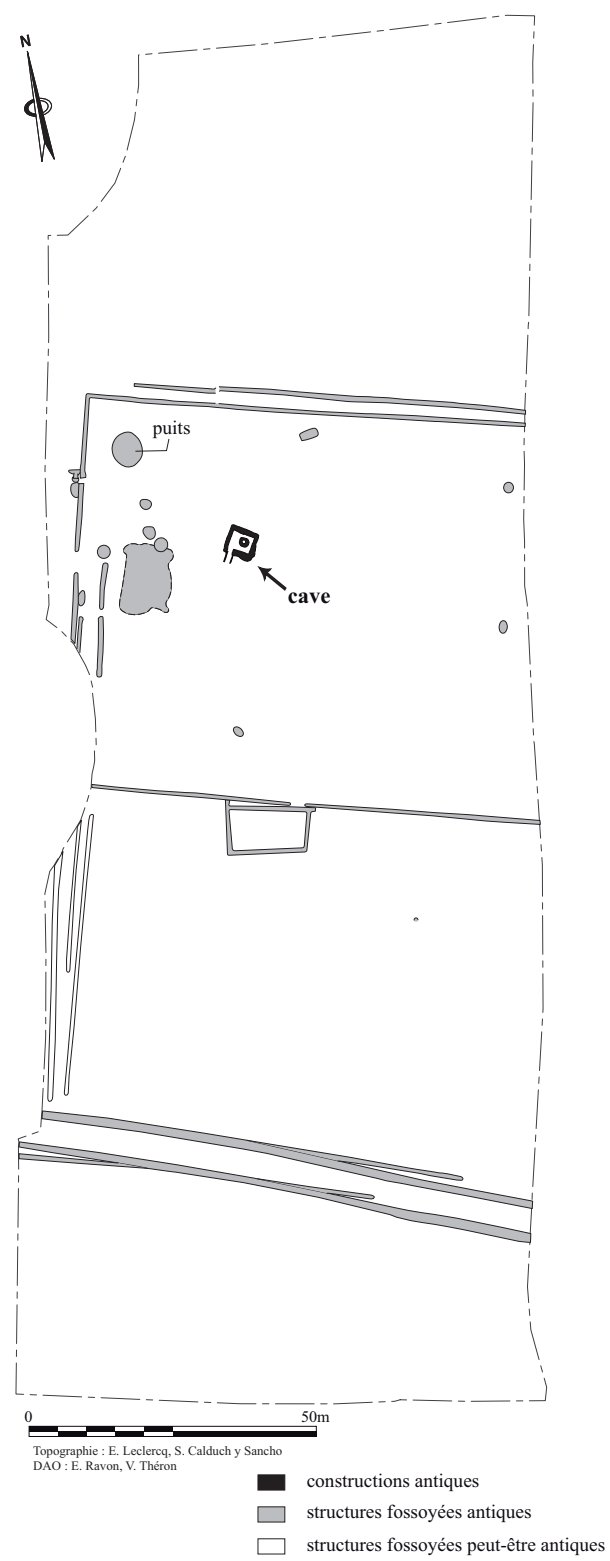

Figure 6 : Plan général des vestiges antiques du site de Val-de-Reuil " la Cerisaie " et localisation de la cave.

Figure 6: General plan of the Roman remains at Val-de-Reuil "la Cerisaie" and location of the cellar. petits silex informes, noyés dans un bain de mortier. Ce mortier de chaux possède une teinte beige légèrement jaune rosé et un granulat composé à parts égales de quartz et de silex. Sa composition révèle un choix de matières premières locales dont l'extraction a pu s'effectuer dans les formations superficielles du plateau, au plus près du site (Coutelas, in Lukas (dir.), 2010, tome II, p. 275). Ce mortier a été également employé en parement pour les joints entre les silex et moellons et, par endroits, soulignés au fer par les constructeurs.

Les deux soupiraux ou niches ont été installés plus ou moins au centre et dans l'épaisseur des murs méridional et occidental. Côté sud, il n'en subsiste que deux moellons en calcaire de part et d'autre d'une ouverture large de 1,45 mètre, et dont la base est située à une hauteur de 1,30 mètre par rapport au sol. Les moellons calcaires de petit appareil qui forment son encadrement sont disposés selon un angle d'environ 60 degrés par rapport à l'axe du mur. Étant donné l'état de conservation médiocre de cet ensemble, il est délicat de préciser sa nature : niche fermée ou soupirail communiquant avec l'extérieur? Le mur nord n'a, pour sa part, conservé aucun moellon calcaire in situ mais des indices indirects plaident en faveur d'un aménagement similaire : il s'agit d'une forte concentration d'éclats et de nodules calcaires à l'extérieur et contre ce mur, qui pourraient correspondre aux maigres restes de l'encadrement d'une niche ou d'une ouverture à situer dans la moitié centrale de ce pan de mur. Le remblai déposé à cet endroit renfermait de nombreux silex mais également quelques débris calcaires probablement associés à cet aménagement.

L'accès de cette cave, large de 0,90 mètre, est précédé d'une pente inclinée à 45 degrés dans la partie supérieure puis à 75 degrés dans la moitié inférieure, qui accueillait manifestement un escalier en bois. Les deux trous de poteau, profonds d'une cinquantaine de centimètres, situés à deux mètres en avant des piédroits de la baie d'accès, constituaient probablement les points d'ancrage de ses montants. Toutefois, la fonction première de ces derniers pourrait être le support d'une toiture pour l'escalier. Le seuil de porte, haut d'une trentaine de centimètres, était aménagé à même le substrat et ne comportait aucune trace d'un revêtement en pierre ou en bois. Le sol de la cave n'a pas d'aménagement particulier : il correspond aux argiles à silex naturelles sur lesquelles repose une mince couche d'occupation limonoargileuse, rouge-ocre et compacte, qui s'épaissit en avant de l'entrée pour rejoindre, en légère pente, le seuil (us 11013, fig. 13 et 14). À l'extérieur, ce niveau hétérogène se présente sous forme d'une couche horizontale, épaisse d'une dizaine de centimètres (us 12005). 


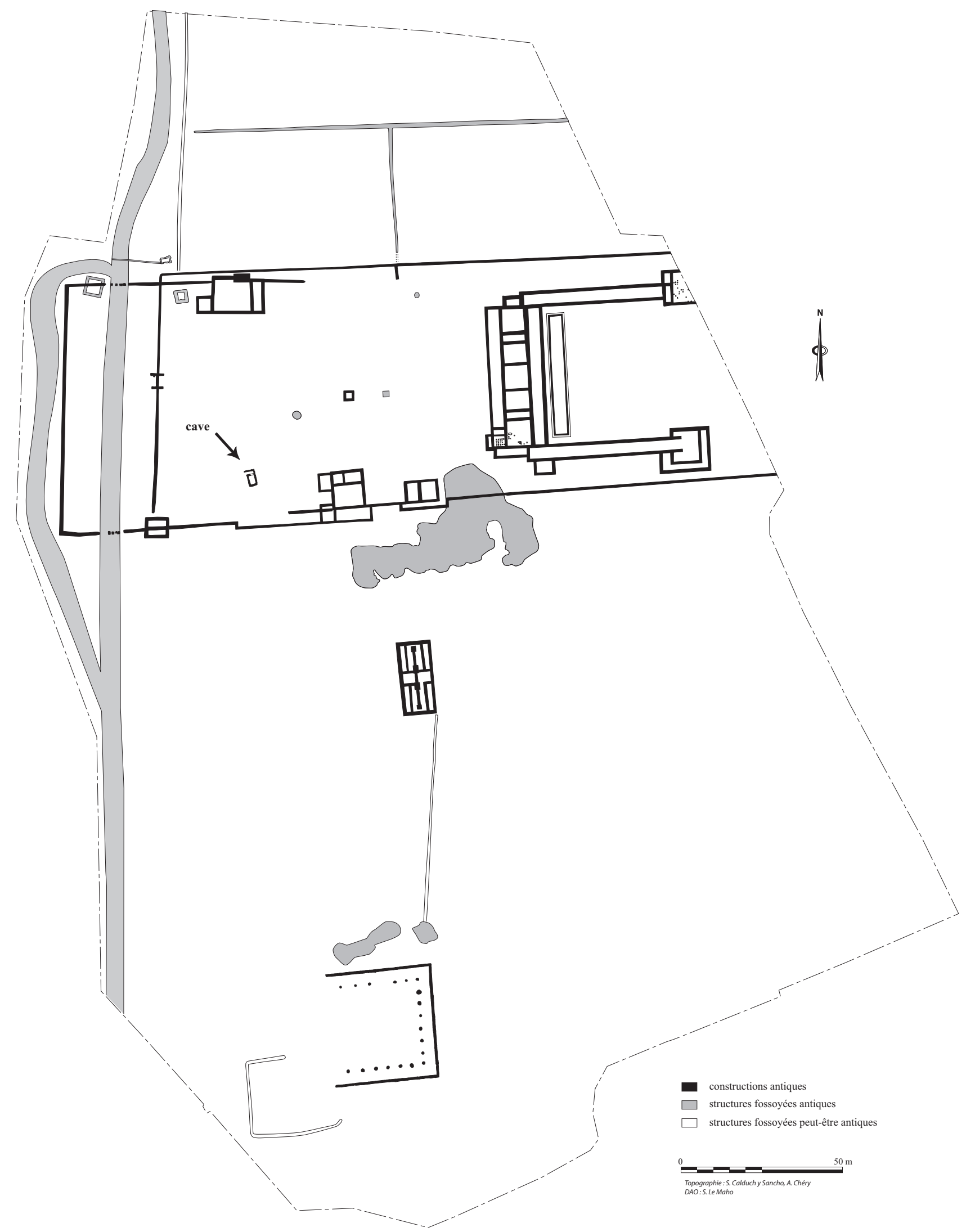

Figure 7 : Plan général de l'occupation antique de Val-de-Reuil «Chemin aux Errants » et localisation de la cave. Figure 7: General plan of the roman site of Val-de-Reuil "Chemin aux Errants" and location of the cellar. 


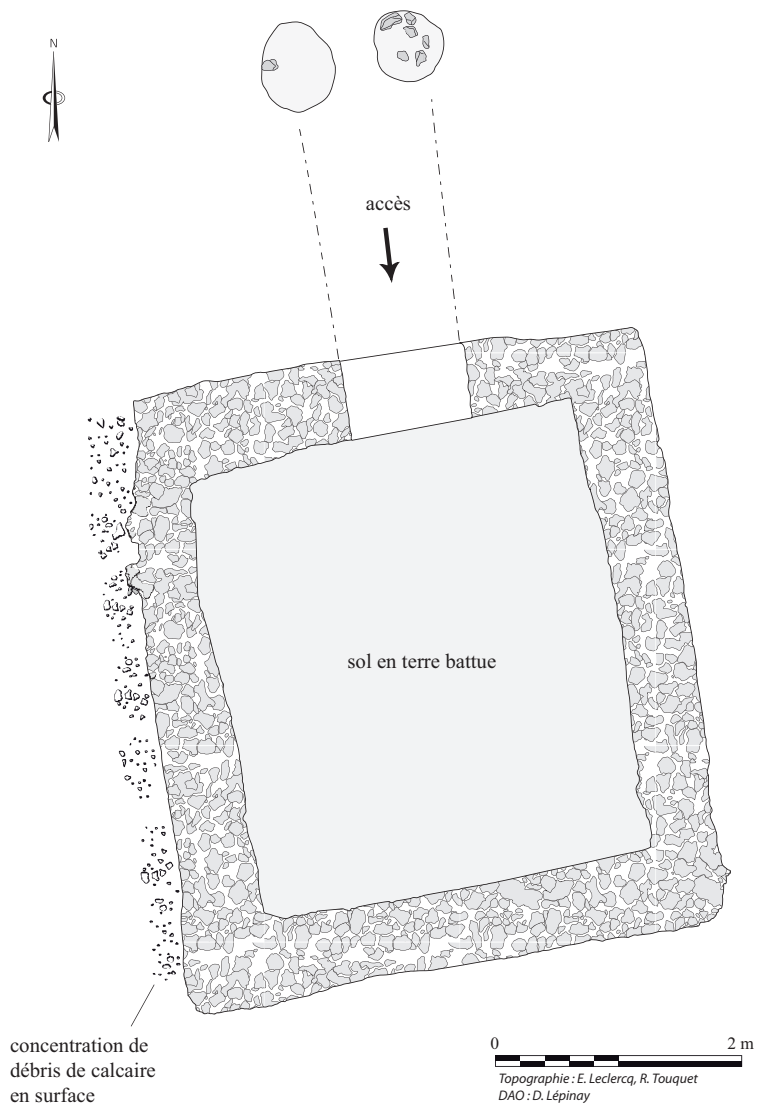

\section{La cave d'Isneauville}

Sa construction est associée à l'agrandissement arrière du petit bâtiment résidentiel formant le cœur de l'occupation. Ses dimensions extérieures sont de 6,45 x 4,4 mètres tandis que l'intérieur mesure 2,70 x 4,65 m, soit 12,5 mètres carrés. L'ensemble est conservé sur environ 1,65 mètre de hauteur. Si l'on restitue une hauteur sous plafond de deux mètres, son volume serait alors de 25 mètres cubes. Cette cave présente plusieurs particularités, notamment architecturales : dans son état originel, elle ne se compose en effet que de trois murs, l'un des grands côtés, à l'ouest, n'ayant pas été édifié (fig. 15 et 16). Étant donné la configuration de l'ensemble et l'installation de la cave à l'aplomb de la façade arrière

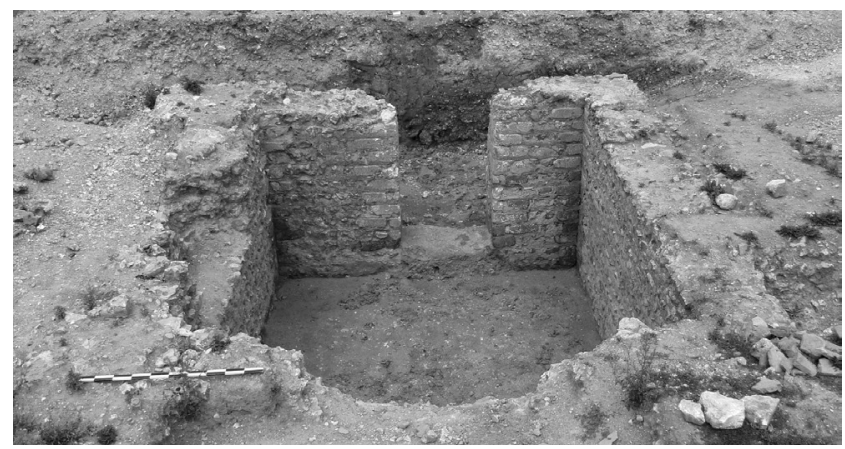

Figure 9: Vue de l'entrée de la cave de Parville (D. Lukas). Figure 9: View of the Parville cellar entrance.

Figure 8 : Plan de la cave antique de Parville.

Figure 8: Plan of the roman cellar of Parville.

Figure 10 : Vue isométrique de la cave de Parville.

Figure 10: Isometric view of the Parville cellar.

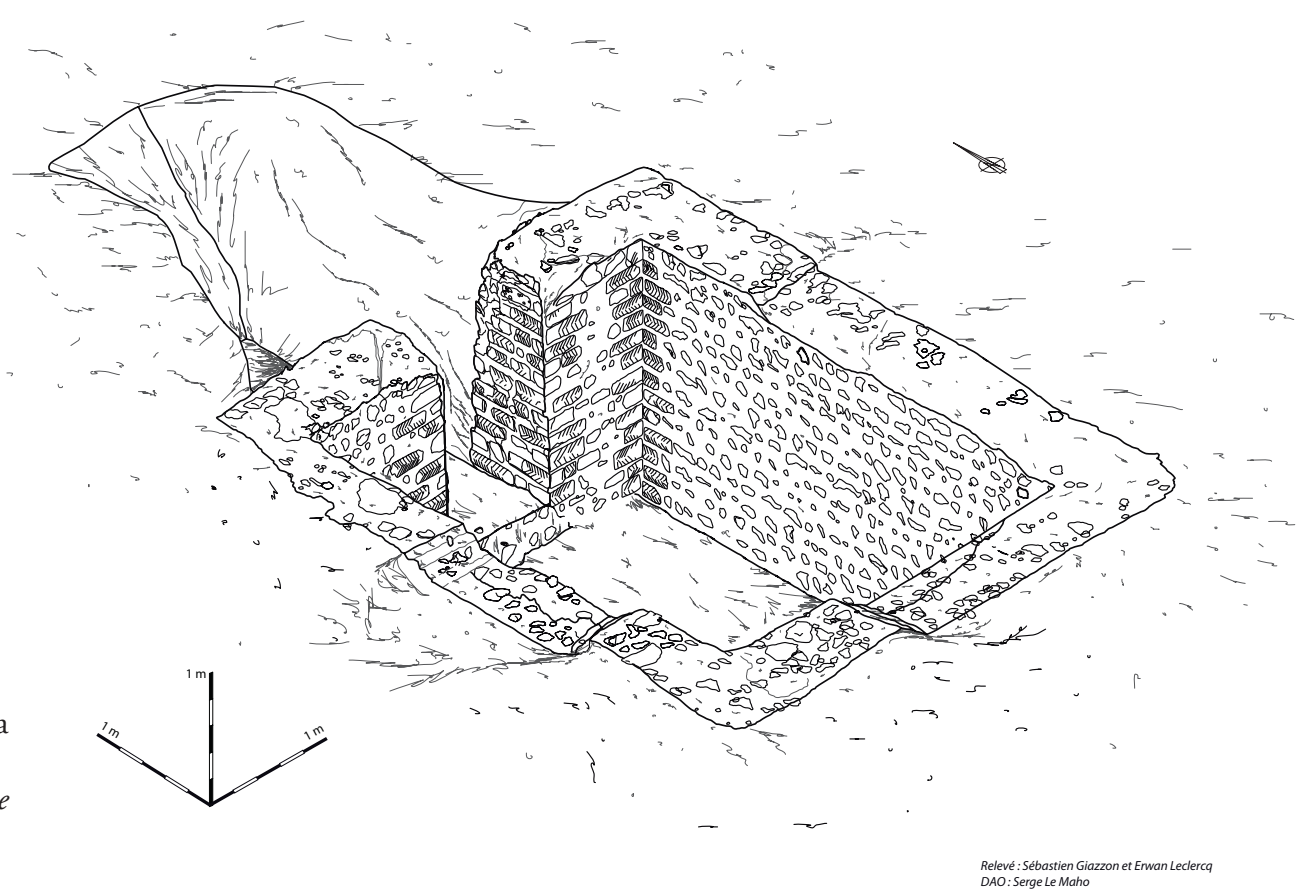


$134,16 \mathrm{~m}$.

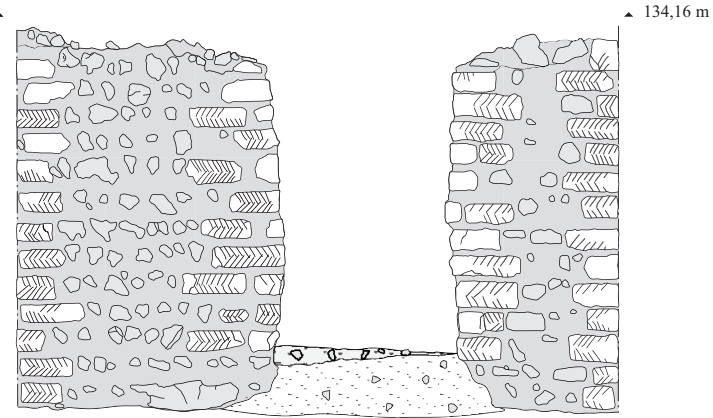

vue intérieure de l'entrée du bâtiment

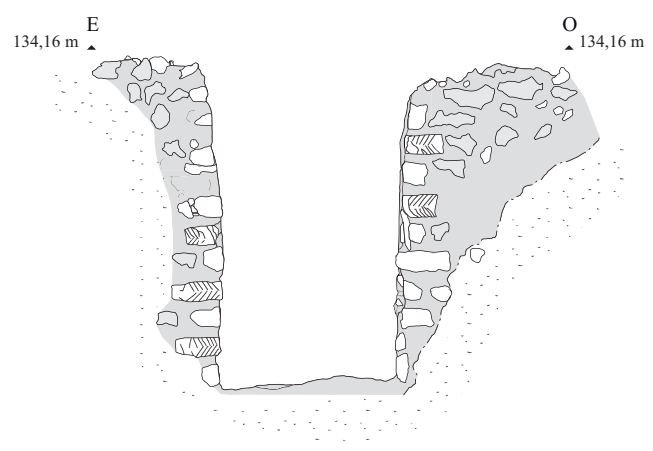

vue extérieure de l'entrée du bâtiment

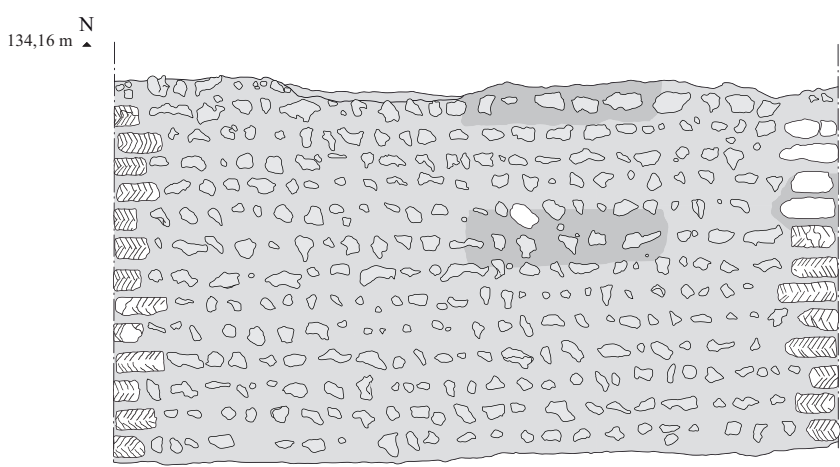

élévation est intérieure
S $134,16 \mathrm{~m}$
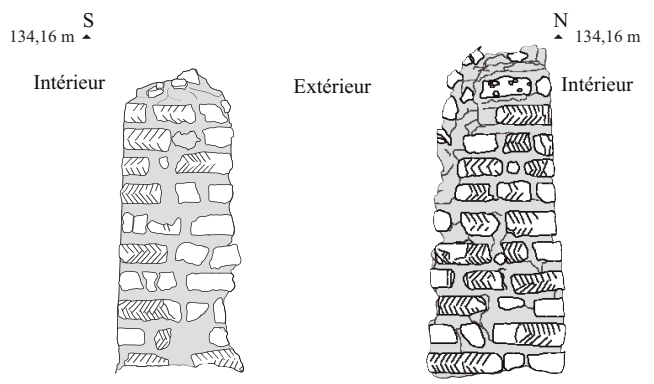

jambages de porte
134,16 m E

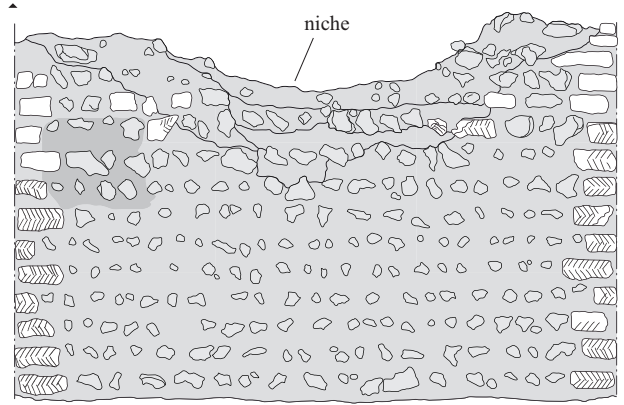

élévation sud intérieure

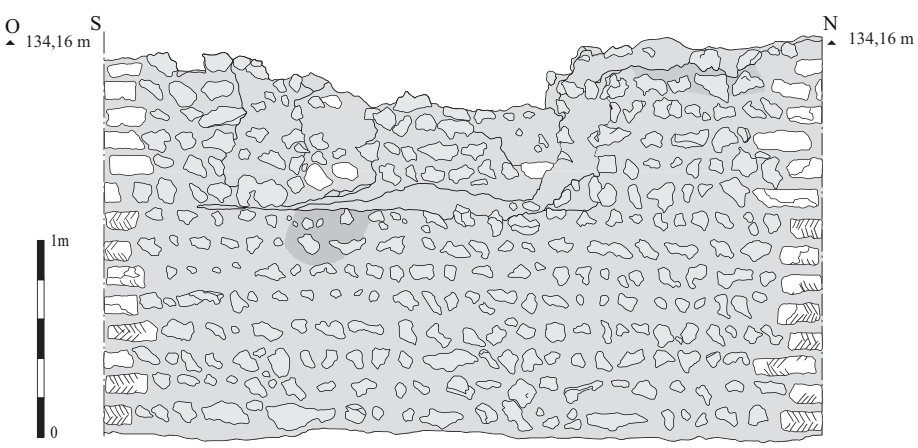

élévation ouest intérieure
silex
$\square$ moellon calcaire
QVI] moellon calcaire avec traces de taille traces de chauffe

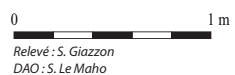

Figure 11 : Élévations de la cave de Parville.

Figure 11: Elevation of the Parville cellar. 


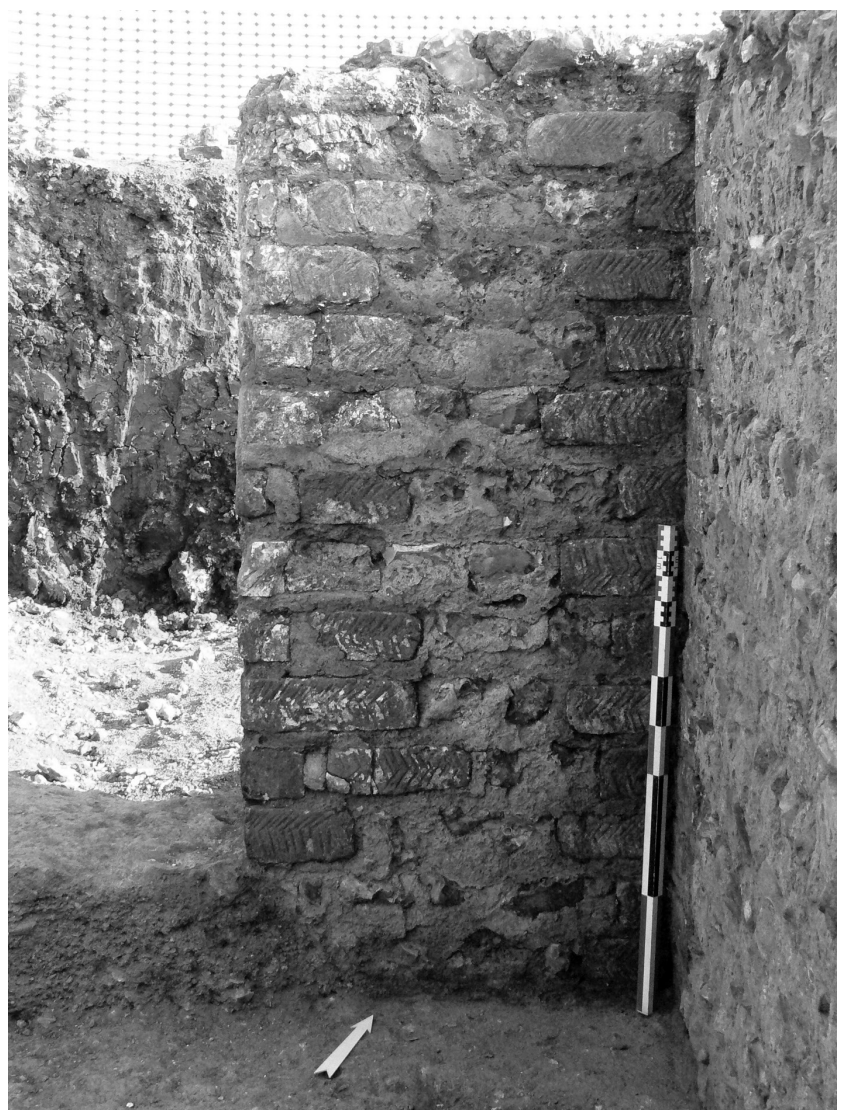

Figure 12 : Jambage de porte de la cave de Parville (D. Lukas). Figure 12: Door downstroke of the Parville cellar.

du bâtiment résidentiel préexistant, il est manifeste que l'absence du quatrième mur découle de l'impossibilité de le construire pratiquement en sous-œuvre. Dans ces conditions, la plus grande partie de la paroi ouest paraît donc, à première vue, avoir été formée par le terrain naturel décaissé à l'aplomb de la fondation, ce qui est pour le moins improbable. L'existence d'un appareillage en bois contre la paroi du terrain naturel est vraisemblable mais ne peut être prouvée, faute de trace d'un dispositif d'ancrage dans les murs initiaux ou dans le sol. Celui-ci a toutefois pu être détruit au moment de la construction du mur plaqué a posteriori. En tout cas, cet agencement n'a pas donné satisfaction et c'est sans aucun doute la raison pour laquelle un mur sera rajouté un peu plus tard sur tout ce côté ouest de la cave, très probablement afin de contrecarrer la poussée exercée par le poids de l'édifice principal (cf. infra).

Les profils des deux murs principaux (nord et est) sont légèrement trapézoïdaux : leur épaisseur augmente de haut en bas de 0,50 mètre à 0,70 mètre. Dans le premier état de la cave, les maçonneries associent un parement de blocs de craie grossièrement taillés, reposant en partie basse sur quatre assises de silex formant un coffrage pour un blocage de silex noyé dans un mortier orangé (fig. 17 à 19). La mise en œuvre de silex en partie inférieure traduit aussi bien la volonté d'asseoir solidement la maçonnerie que de limiter les remontées capillaires. Mais ceci n'évitera pas les problèmes d'humidité sur certaines parties de mur, en particulier sur le grand mur est, comme en témoignent les importantes réfections du parement calcaire, qui montrent par ailleurs que ces dégradations sont bien contemporaines à l'utilisation de la pièce (fig. 17).

De construction soignée mais peut-être fragile, cette cave est, dans un deuxième temps, renforcée par l'adjonction d'un mur sur tout le côté ouest (fig. 15). Dans l'angle nord-ouest, le nouveau mur est directement plaqué contre l'ancien, après léger décaissement du sol en craie et chaux. Ce mur rajouté est plus étroit que le premier tandis qu'il met en ouvre des matériaux de manière différente : il est en effet entièrement constitué de blocs de craie liés avec deux mortiers différents, un mortier de tuileau rouge-orangé, plus hydraulique, dans la partie basse et un mortier jaunâtre pour le reste de l'élévation (fig. 17). Parallèlement, quatre pièces de bois sont engagées dans la maçonnerie de ce nouveau mur, à environ 0,60 mètre les unes des autres. Ces pièces, dont l'emplacement ainsi que le négatif étaient parfaitement visibles dans le mur, correspondent à des petits madriers presque parfaitement carrés de 8 à $11 \mathrm{~cm}$ de section, engagés sur toute la hauteur du mur ainsi que légèrement planté dans le terrain naturel sous-jacent. Cette structure de bois ainsi incorporée dans la maçonnerie était destinée à la rigidifier, en l'empêchant notamment de se déformer sous l'action des poussées exercées par le bâtiment résidentiel déjà construit. La taille des pièces de bois reste modeste, mais leur faible espacement (env. 0,60 m) la compense, surtout si l'on considère qu'elles ont pu être reliées les unes aux autres par une ou deux traverses horizontales, et qu'elles étaient sans doute solidaires des poutres supportant le plancher de la pièce située au-dessus.

Sans qu'aucune relation ne soit établie avec ce dispositif, un alignement très sommaire de pierres est ensuite posé au sol, le long de ce nouveau mur (fig. 15 et 20). La stratigraphie montre que cet aménagement léger est postérieur à la cloison transversale ancrée dans le sol originel, mais antérieur au dépôt de l'épais niveau d'occupation formé sur tout le sol de la pièce. Situé exactement au droit des quatre pièces de bois engagées dans le mur, ce "solin " rudimentaire ne peut être clairement caractérisé (fig. 20). Sa participation à un dispositif de rangement adossé au mur est toutefois vraisemblable, d'autant que son emplacement coïncide en partie avec une nette différence d'usure du lait de chaux recouvrant le sol en craie damée, prouvant qu'il a constitué pendant un certain temps une sorte de contrainte à la circulation dans la pièce, avant que le sol ne soit recouvert d'un niveau de terre battue. 

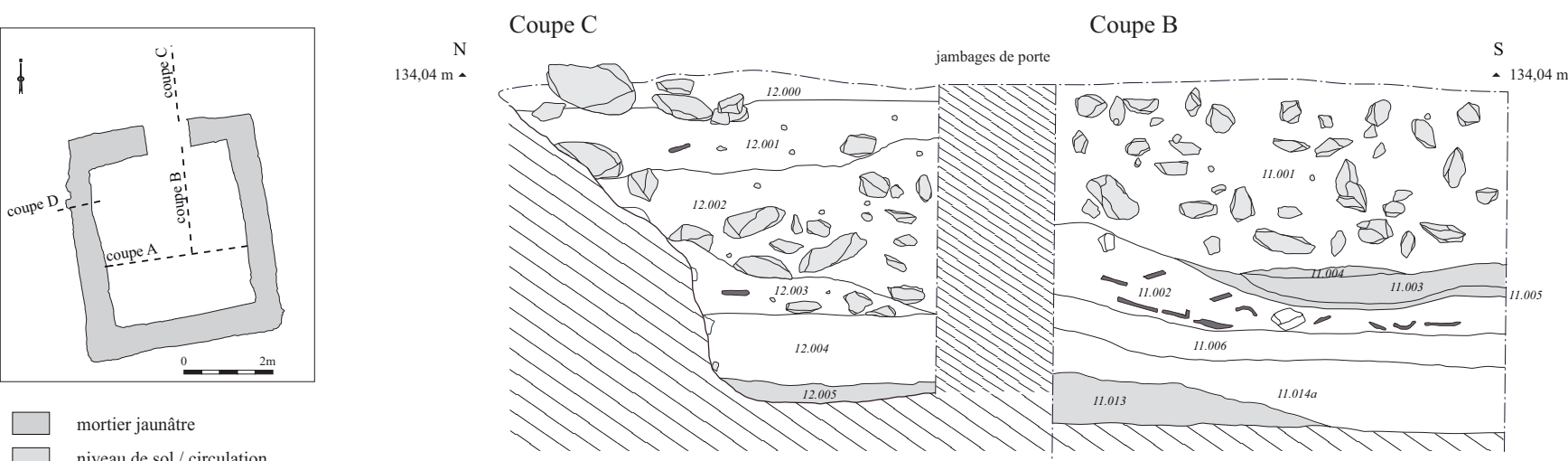

niveau de sol / circulation

maçonnerie

argile jaune-orangé à silex

cailloutis de silex

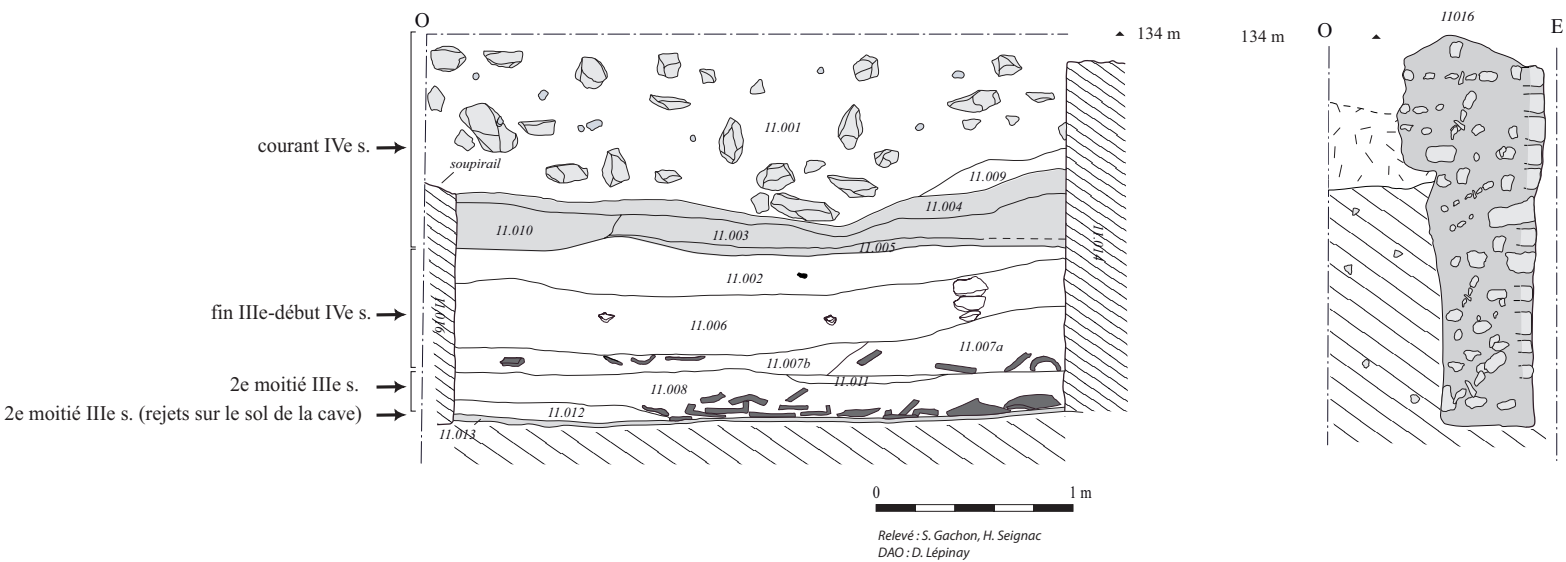

11.001: limon argileux brun-gris avec débris de construction (nombreux rognons de silex et blocs calcaires taillés et bruts, blocs de mortier et éléments de TCA), crustae, céramique (NR28), 1 monnaie, clouterie, outillage.

11002: limon gris argileux, meuble, hétérogène et très organique avec beaucoup de charbons de bois, rejets de faune et coquillages,

céramique (NR70), verreries, 1 monnaie, clouterie, objets de menuiserie, meule en basalte, moellons calcaires, TCA (tegulae, joints de tuiles), macrorestes, battitures.

11003: limon fin sableux, orangé et très meuble, céramiques (NR9), charbon de bois, tôle en alliage cuivreux.

11004: limon bleu-gris renfermant quelques petits silex brûlés, des charbons de bois et coquillage.

11005: limon brun foncé et organique avec traces de charbon de bois, 32 tesson.

11006: limon sablo-argileux avec débris de construction (dont de nombreux blocs calcaires, blocs de mortier gris-brun et petits silex),

nombreux charbons de bois, céramique (NR110), verreries (NR6), 8 monnaies, rejets de faune (bois de cerf), éléments en fer et bronze (outillage, quincaillerie, transport).

11.007a : limon ocre argileux, TCA (dont tubuli), petits silex, enduits peints, céramique, faune, verre, métal (clouterie, quincaillerie...)

11007b: limon argileux brun-gris, céramique, verreries, 11 monnaies, faune, métal (clouterie, quincaillerie...).

11.008: limon argileux brun avec nombreuses TCA (tegulae et imbrices), éléments en fer (quincaillerie et clouterie), 1 monnaie

perforée, céramique (NR171), faune, verre.

11.009: matrice limoneuse à argileuse, brun-gris.

11.010: limon fin sableux, très meuble et très charbonneuse, 2 tessons.

11.011: fine couche charbonneuse.

11.012: limon brun-jaune argileux compact avec nodules calcaires et silex, 2 tessons et éléments de clouterie.

11013: limon argileux rouge-ocre avec cailloutis très compact, céramique (NR18), éléments de clouterie et de quincaillerie.

11014a: limon argileux très compact, céramique (NR15) et éléments de clouterie.

12.001: limon brun foncé meuble avec nombreux débris de construction (silex, blocs calcaires, TCA...), céramique (NR24), verre

(NR4), rejets de faune et malacofaune, éléments de clouterie et de quincaillerie.

12.002: limon brun avec débris de construction (gros silex et blocs de mortier), céramique (NR21), verre, éléments en fer (clouterie et quincaillerie).

12.003: limon brun-jaune avec rognons de silex et TCA, céramique (NR4), éléments de clouterie.

12.004: limon argileux brun-jaune, homogène et compact, céramique (NR11), éléments de clouterie, quincaillerie et outillage.

12.005: limon argileux brun-rouge, homogène et compact avec cailloutis de silex.

Figure 13 : Coupes stratigraphiques du comblement de la cave de Parville.

Figure 13: Stratigraphical section of the Parville cellar fill. 


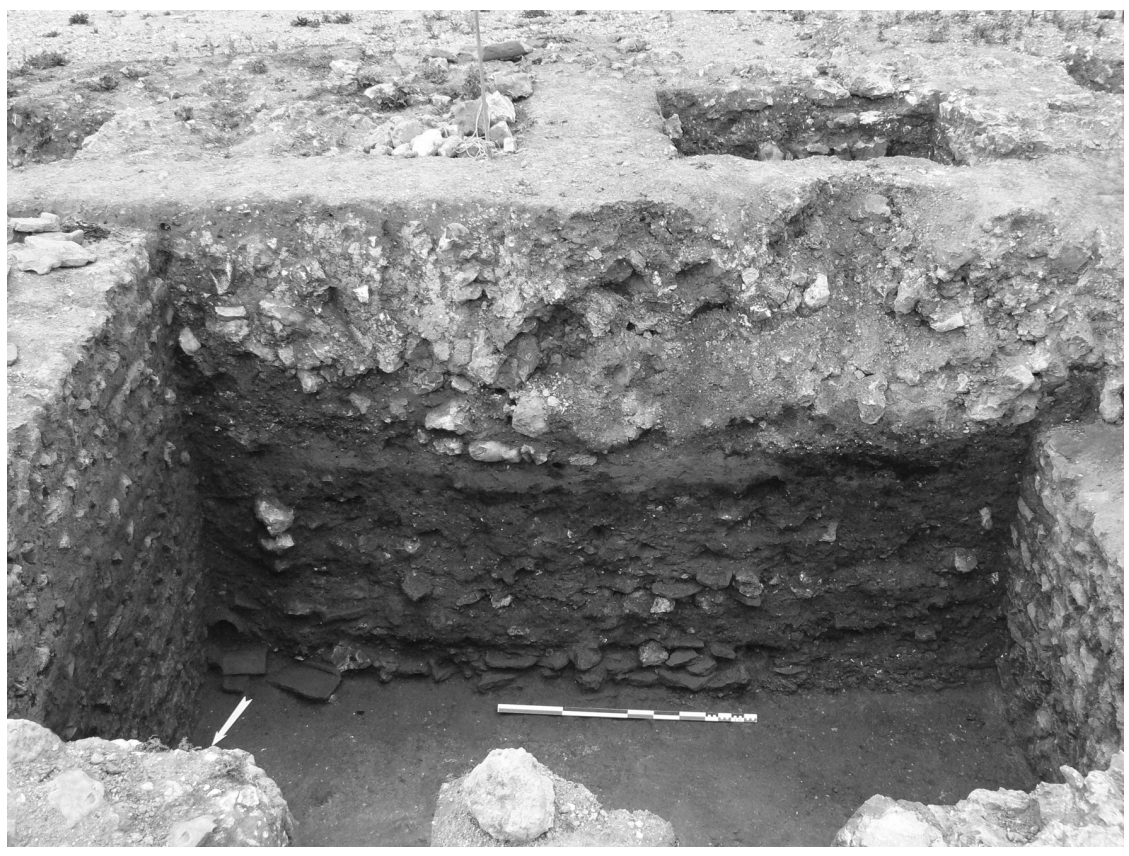

Figure 14 : Vue des séquences stratigraphiques du comblement de la cave de Parville (D. Lukas).

Figure 14: View of the stratigraphical sequence of the Parville cellar fill.
L'escalier est quant à lui formé d'une structure en bois, dont l'emplacement était visible du côté ouest, où un alignement de blocs associés à deux fiches en fer encore en place présente une inclinaison régulière, sans doute liée à celle du limon d'escalier. Du côté est, un surcreusement de forme triangulaire semble lié à la construction de la maçonnerie orientale de la cave, mais pourrait aussi avoir servi à l'ancrage partiel de l'autre côté du montant d'escalier dans le terrain naturel, comme le suggèrent des clous recueillis en trois endroits. Le comblement de cette grossière tranchée de fondation a livré de la céramique caractéristique du milieu ou du troisième quart $\mathrm{du} \mathrm{II}^{\mathrm{e}}$ siècle qui fournit un repère chronologique appréciable pour situer cet aménagement et, indirectement, la construction de la cave à peu près à cette période. Le bas de l'escalier en bois reposait sur une marche en maçonnerie formée par le haut du mur sud chaîné au mur est, lissé au mortier à cet effet (fig. 15, 17 et 19). Cette marche était scellée par le même niveau d'occupation que celui couvrant le reste du sol de la cave, prouvant son utilisation comme telle.

Au sol de la pièce, une couche de craie damée recouverte par un lait de chaux a été étalée après un léger décaissement de la surface centrale. Ce sol, épais d'au maximum $12 \mathrm{~cm}$, remonte au contact des murs, sans les toucher. Resté complètement intact dans la moitié occidentale de la pièce, mais fortement usé dans la moitié orientale (la chaux avait disparu et la craie était fortement polie par les passages), ce sol de cave a ensuite été recouvert par une couche de " terre battue " riche en débris céramiques et fauniques (restes de moules et d'huîtres, os de poissons et de volatiles). Quelques graines piégées dans ce niveau révèlent la présence de céréales et de noisetier (Zech-Matterne, in Adrian, 2011, p. 279). Les céréales sont ici moins abondantes que dans l'un des premiers remblais de comblement de la cave qui montre notamment la présence d'éléments panifiés (us 14, fig. 19). Le lot de céramiques, assez important avec plus de 400 restes parfois bien conservés, fixe la formation de ce niveau d'occupation entre la fin $\mathrm{du} \mathrm{II}^{\mathrm{e}}$ et les premières décennies $\mathrm{du}$ III $^{\mathrm{e}}$ siècle. Outre le repère chronologique fourni, l'ensemble apporte une indication intéressante en révélant une très nette surreprésentation des céramiques fines (pas moins de $56 \%$ du NMI), qu'il s'agisse de sigillées ( $28 \%$ ) ou de parois fines engobées/métallescentes $(28 \%)$. Si cette proportion peut être mise en rapport avec la fonction résidentielle du bâtiment, elle étonne pourtant au regard de l'image que l'on pourrait avoir de la cave elle-même, une pièce avant tout destinée au stockage des denrées.

\section{La cave de Val-de-Reuil, La Cerisaie}

Il s'agit d'une construction presque carrée mesurant 5,5 x 5 mètres en dimensions extérieures et 3,90 x 3,05 mètres en dimensions intérieures, ce qui lui donne une superficie interne de 12 mètres carrés tant les murs sont épais. Ces derniers sont formés d'une maçonnerie de pierres sèches présentant un parement de blocs calcaires irréguliers et tout juste équarris, disposés en assises plus ou moins régulières, associé par derrière à un blocage en moellons de silex et de calcaire 


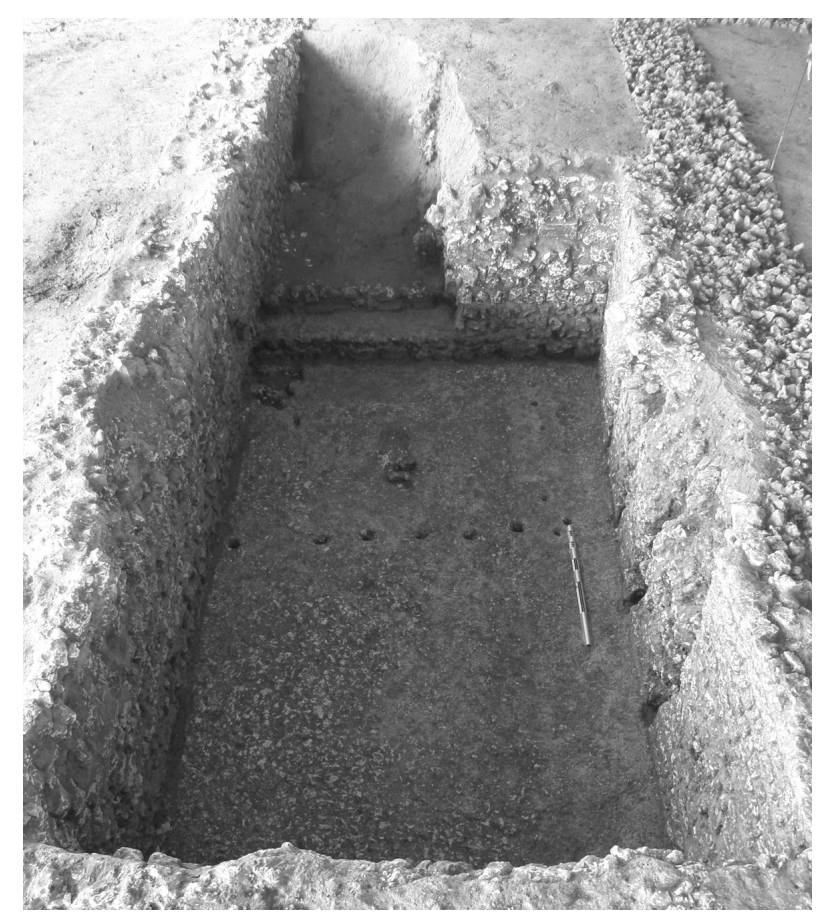

Figure 16: Vue de l'intérieur de la cave d'Isneauville avec traces de piquets au fond (Y.-M. Adrian).

Figure 16: View of the inside of the Isenauville cellar with stake holes in the floor.

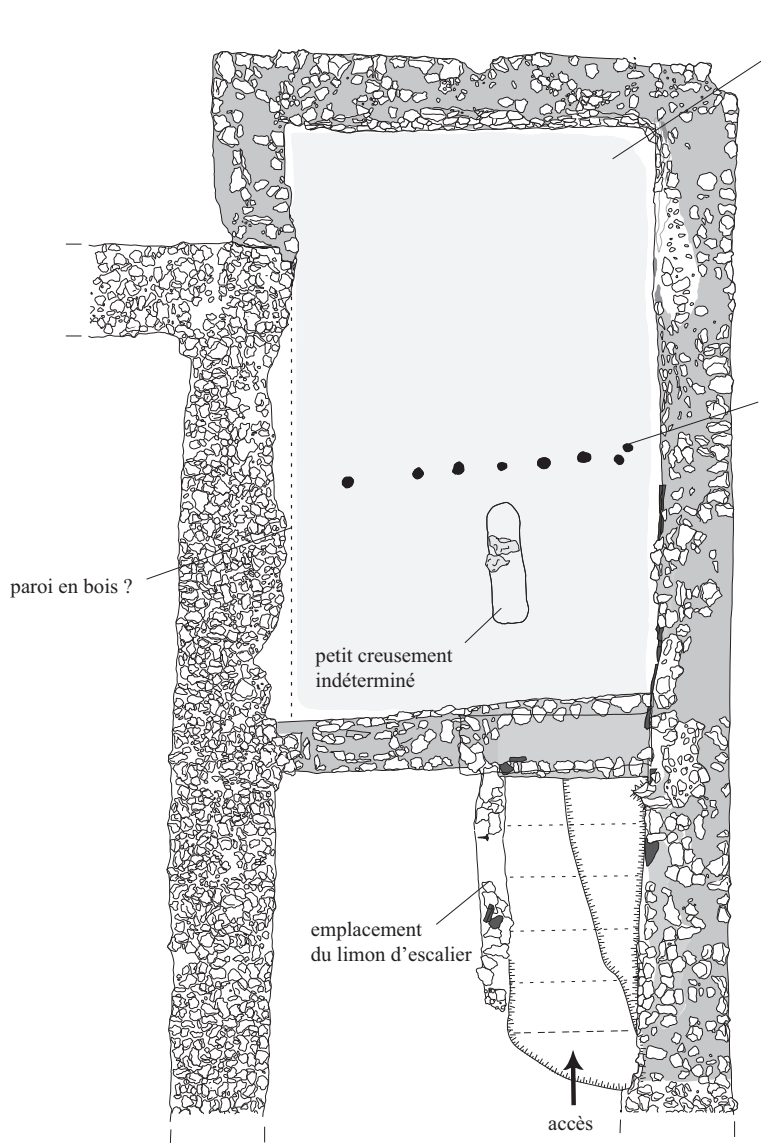

état initial
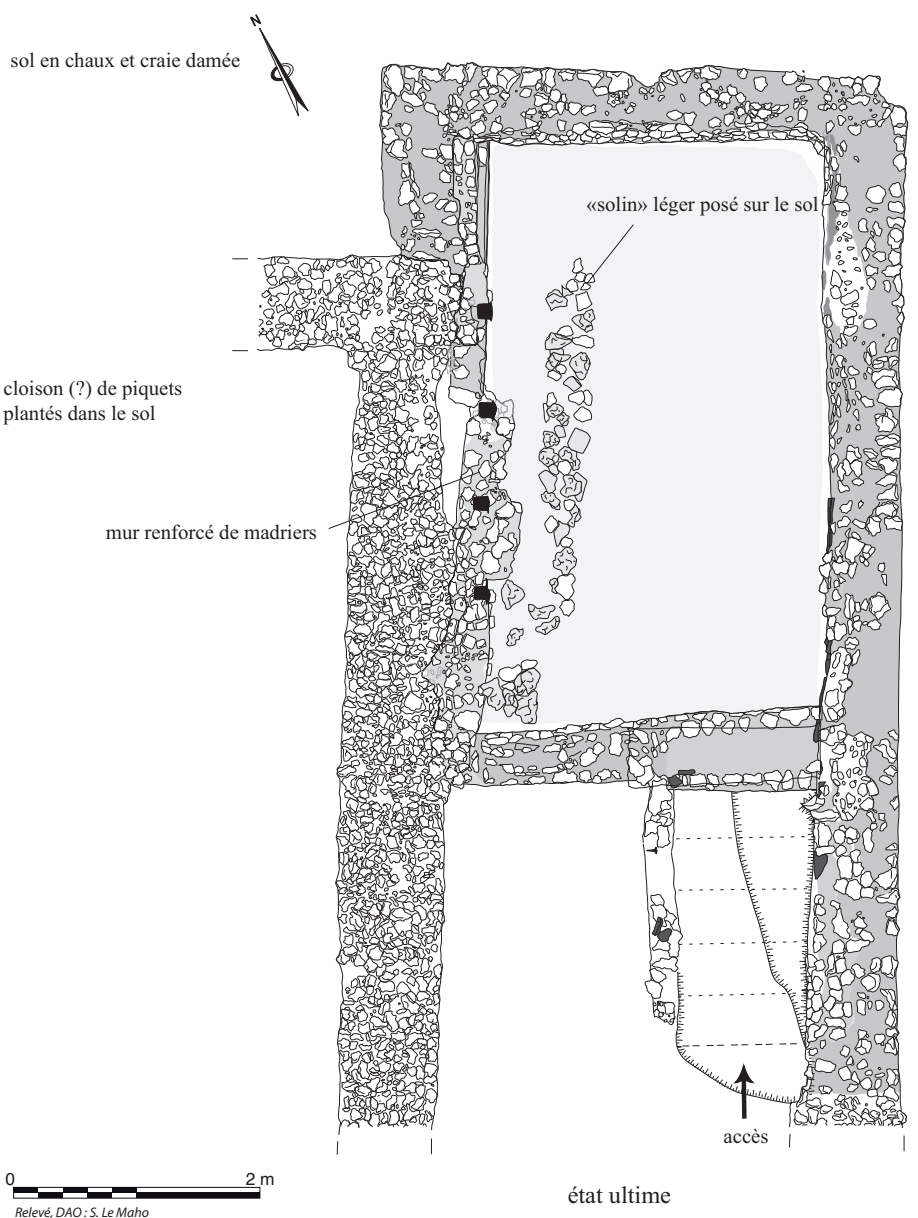

état ultime

Figure 15 : Détails des deux états de la cave d'Isneauville.

Figure 15: Detail of the two phases of the Isneau cellar. 

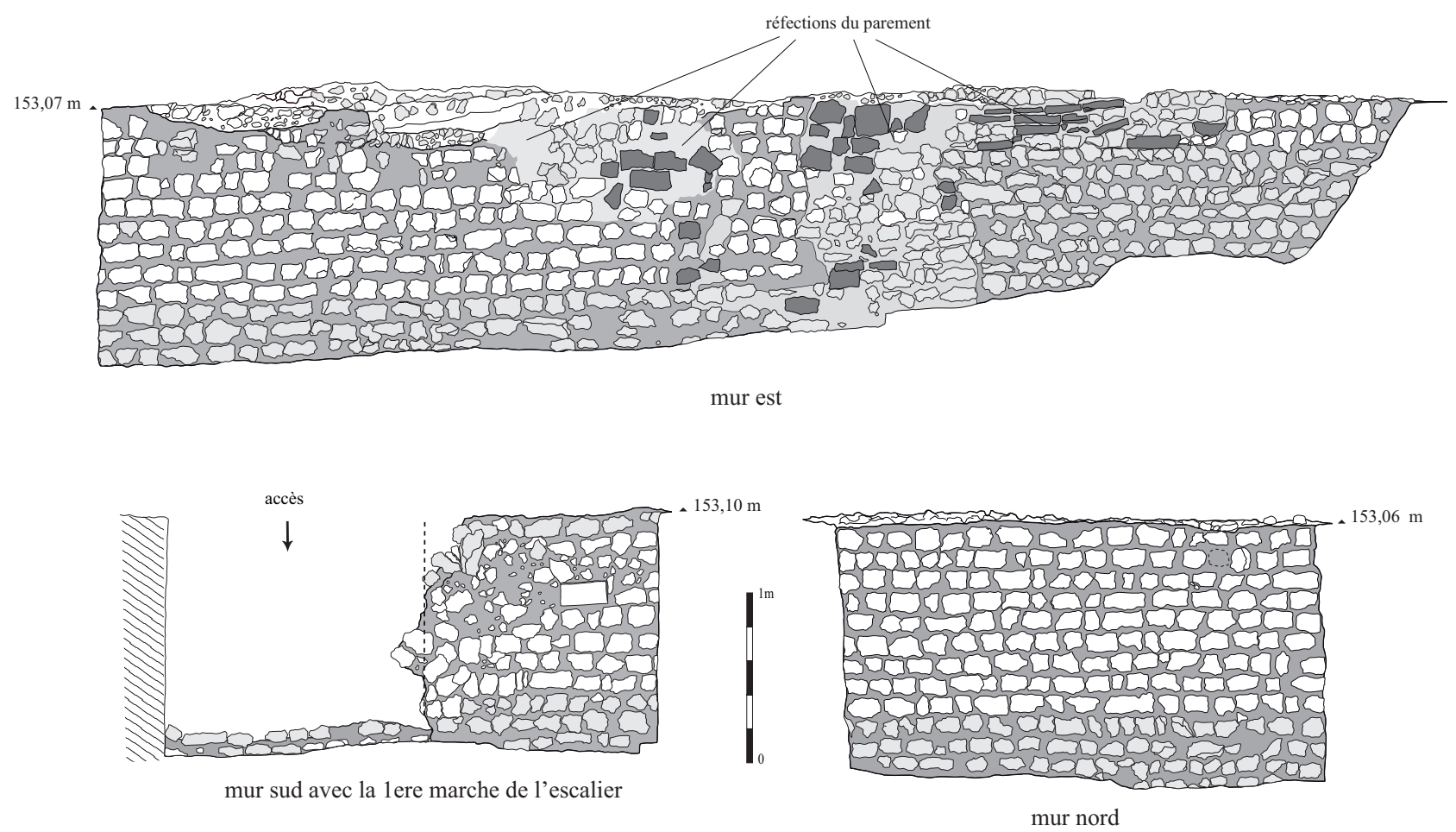

mur sud avec la 1ere marche de l'escalier

mur nord

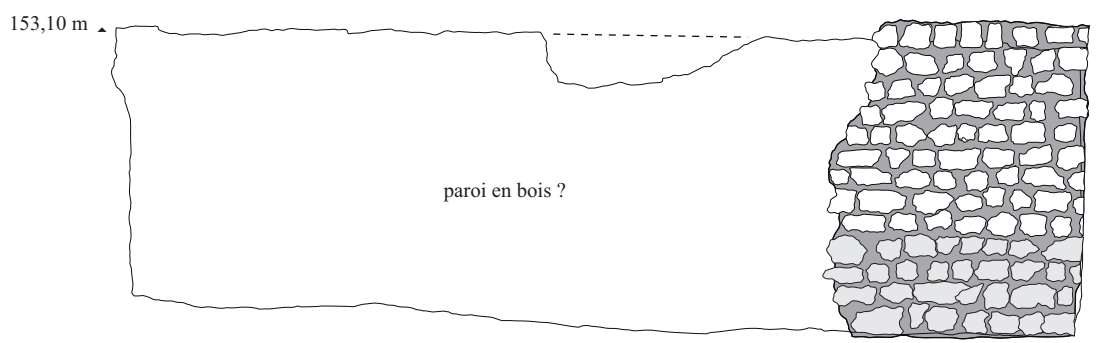

mur ouest dans son état initial
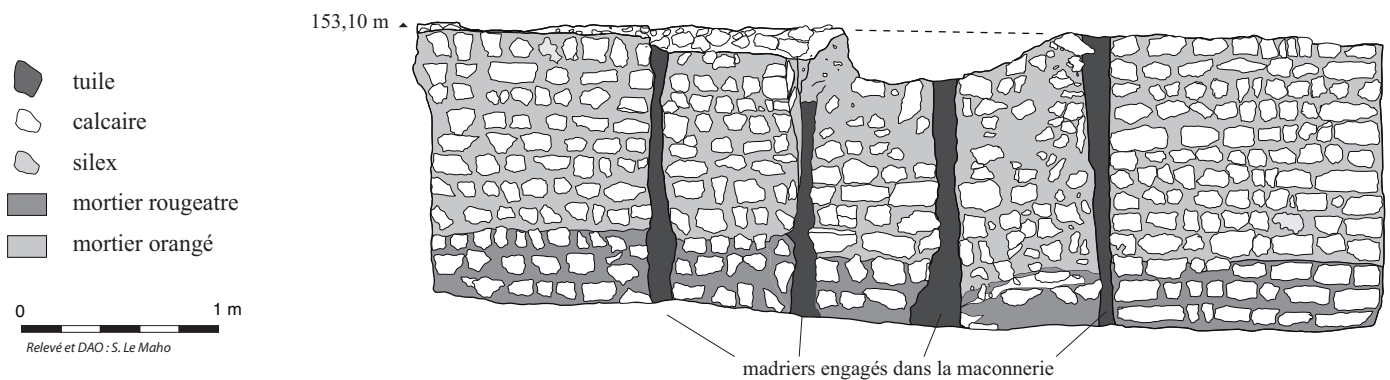

mur ouest après placage d'un nouveau mur

Figure 17 : Élévations de la cave d'Isneauville.

Figure 17: Elevation of the Isneauville cellar. 


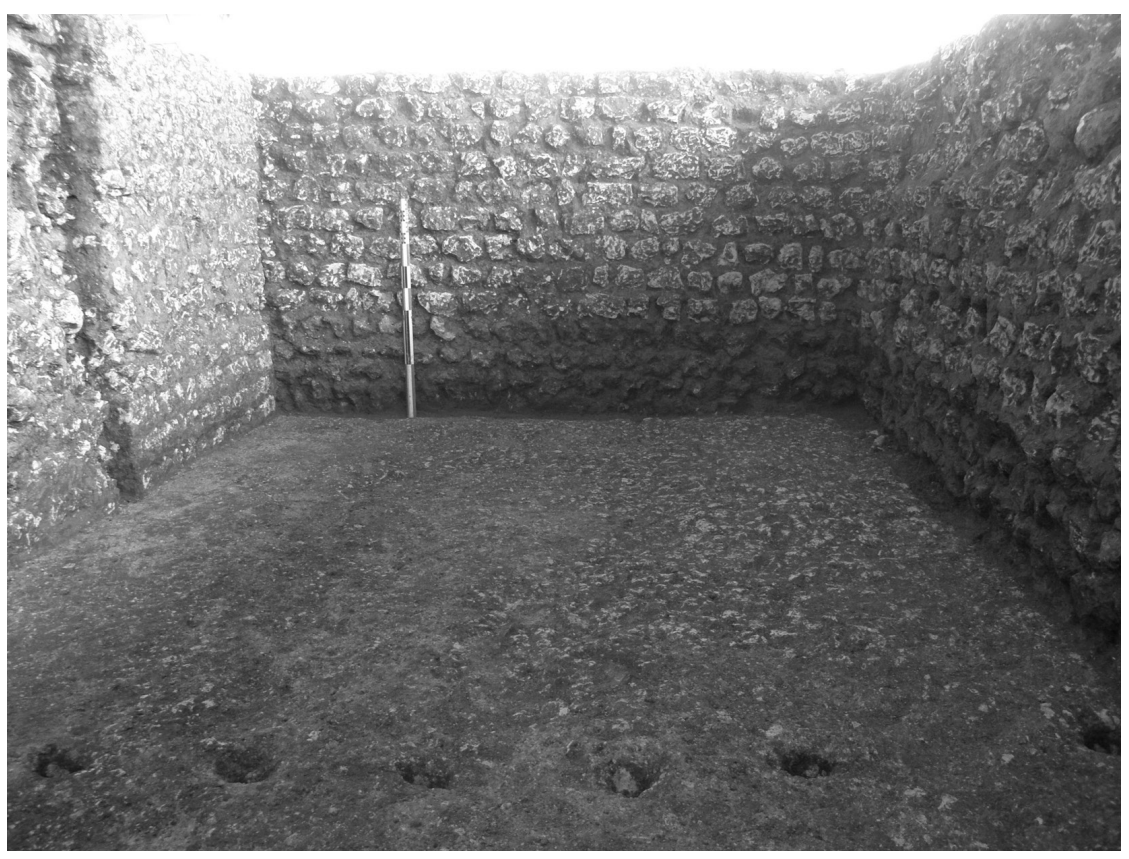

Figure 18 : Élévations et sol en craie damée de la cave d'Isneauville (Y.-M. Adrian).

Figure 18: Elevation and packed chalk floor of the Isneauville cellar. (fig. 21 et 22). L'épaisseur des murs est très irrégulière : elle est de 0,70 mètre pour le mur ouest, d'1 mètre pour le mur nord, voire oscille entre 0,65 mètre et 1 mètre pour le mur est, ou même entre 1 mètre et 1,3 mètre pour le mur sud. Ce défaut de symétrie peut être le résultat de l'instabilité des parois sableuses et d'éventuels effondrements à compenser lors de la mise en ouvre, mais il peut aussi résulter d'un manque de soin lors de la construction.

Dans l'angle sud-ouest, un accès de 1,25 mètre de large est aménagé dans le terrain naturel selon une pente à 45 degrés et se termine par une marche de seuil en calcaire (fig. 23). Deux rainures longitudinales, creusées dans le substrat, marquent le logement des montants d'un escalier en bois, en bas duquel se trouvait certainement une porte.

Conservée sur une profondeur de 1,85 mètre, la construction a fait l'objet d'une récupération importante des pierres et les murs ne sont en fait préservés que sur une hauteur variant de 0,70 mètre à 1,25 mètre, suivant les endroits. Dans ces conditions, aucun agencement de type soupirail ou niche n'a pu être identifié. Toutefois, une structure de bois prise dans la maçonnerie a été mise en évidence sur les murs ouest et est, qui ont reçu chacun un poteau d'un diamètre de 15 à $20 \mathrm{~cm}$ et d'une section rectangulaire pour l'un deux. Ces poteaux sont placés en vis-à-vis et profondément ancrés dans le blocage de la maçonnerie puisque leur fond repose sur la première assise des murs (fig. 22). Ils évoquent des éléments porteurs d'une superstructure en bois mais on s'étonne alors de ne pas identifier d'autres emplacements de poteau placés symétriquement.
À l'intérieur de la cave et en position désaxée par rapport à l'entrée, a été aménagée une cuve circulaire creusée sur 2,65 mètres de profondeur et possédant un diamètre interne de 0,60 mètre pour un diamètre externe de 1,60 mètre (fig. 24). Celle-ci s'ouvre directement au niveau du sol, sans qu'on puisse dire s'il existait ou non une margelle, et elle est maçonnée sur toute sa hauteur au moyen de blocs de silex aux dimensions hétéroclites, assemblés sans mortier. Son comblement se compose du haut en bas d'un sédiment fin, gris et homogène, contenant du mobilier céramique de façon éparse. La fonction de cette structure, immobilisant en grande partie l'espace utile de la cave, reste énigmatique : il ne s'agit certainement pas d'un point de captage d'eau car la nappe phréatique apparaît ici à plus de 15 mètres de profondeur, d'autant qu'un grand puits à eau de 5 mètres de diamètre, situé à proximité immédiate, remplit déjà cet office. En revanche, il est difficile de savoir si elle correspond à une citerne destinée au stockage ou au traitement d'un produit particulier ou si, au contraire, elle a servi de puisard ou puits perdu pour l'évacuation de liquides ou d'eaux usées.

Le fond de la cave n'a livré aucun aménagement de sol et se trouve seulement constitué par la grave caillouteuse et compacte du terrain naturel. Plus étonnant, il ne conserve aucun niveau de circulation ou d'occupation, ni même une couche de destruction résultant d'un effondrement des élévations. Le bâtiment semble avoir été en grande partie démonté peu après son abandon et on peut se demander si l'absence de niveau de sol n'est pas le résultat d'un curage visant la récupération d'un éventuel dallage. À ce sujet, l'étude anthracologique effectuée sur la couche de charbons de bois incluse 


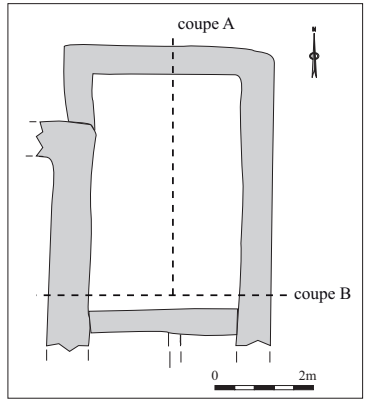

E

coupe B
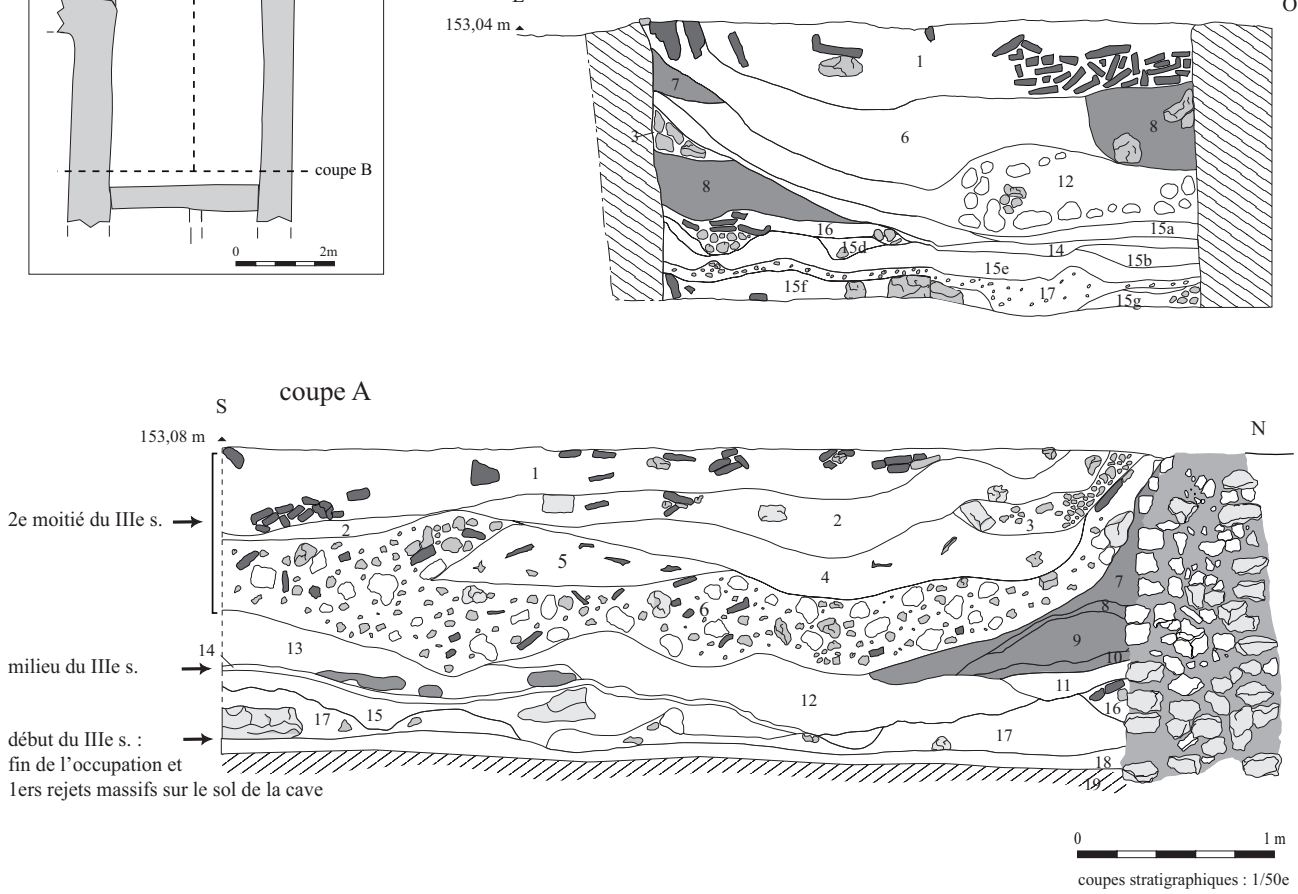

tuile

$\checkmark$ calcaire

silex

mortier rougeâtre

mortier orangé

limon avec enduit de chaux

S

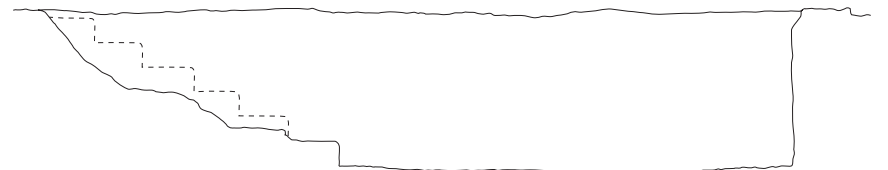

profil de la cave avec son accès
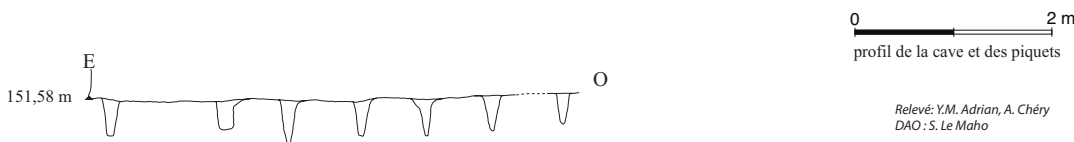

Relevé:Y.M. Adrian, A. Chéry

$D A O:$ : S. Le Maho

profil des piquets pris dans le sol en craie et chaux

Figure 19 : Coupes stratigraphiques et profils de la cave d'Isneauville.

Figure 19: Stratigraphical sections of the Isneauville cellar.
1 : remblai charbonneux avec mobilier dispersé, dont nombreuses tuiles fragmentaires et clous

2 : remblai hétérogène avec des inclusions de mortier beige et orange, enduits, débris fragmentaires de TCA et clous

3 : remblai (ou éboulis ?) de craie et de limon (torchis ?)

4 : idem que 2 mais plus charbonneux

5 : idem mais avec plus de mortier

6 : remblai de démolition avec gros blocs de craie, de silex encore agglomérés de mortier beige, et gros morceaux de mortier beige, morceaux de mortier plus fin, débris d'enduits peints blanc et rouge

7/8/9/10 : limon beige presque stérile parfois aggloméré d'enduit de chaux (torchis des élévations ?)

11 : remblai à dominante limoneuse mais avec nodules de craie et de mortier

12 : remblai hétérogène avec charbons, débris de mortier, quelques TCA et blocs taillés divers (silex et craie)

13 : remblai argileux noirâtre avec très gros charbons,"poches" de limon jaune et nombreux clous

14 : fine couche charbonneuse riche en céramique du côté nord

$15 \mathrm{a}-15 \mathrm{~g}$ : couches limoneuses presque stériles

16 : couche limoneuse avec débris de tuiles

17 : craie broyée pulvérulente avec quelques blocs chauffés épars

18 : niveau argileux gris avec fins débris (niveau d'occupation de la cave, partiellement visible sur cette coupe)

19 : couche de chaux et craie damée (sol) 


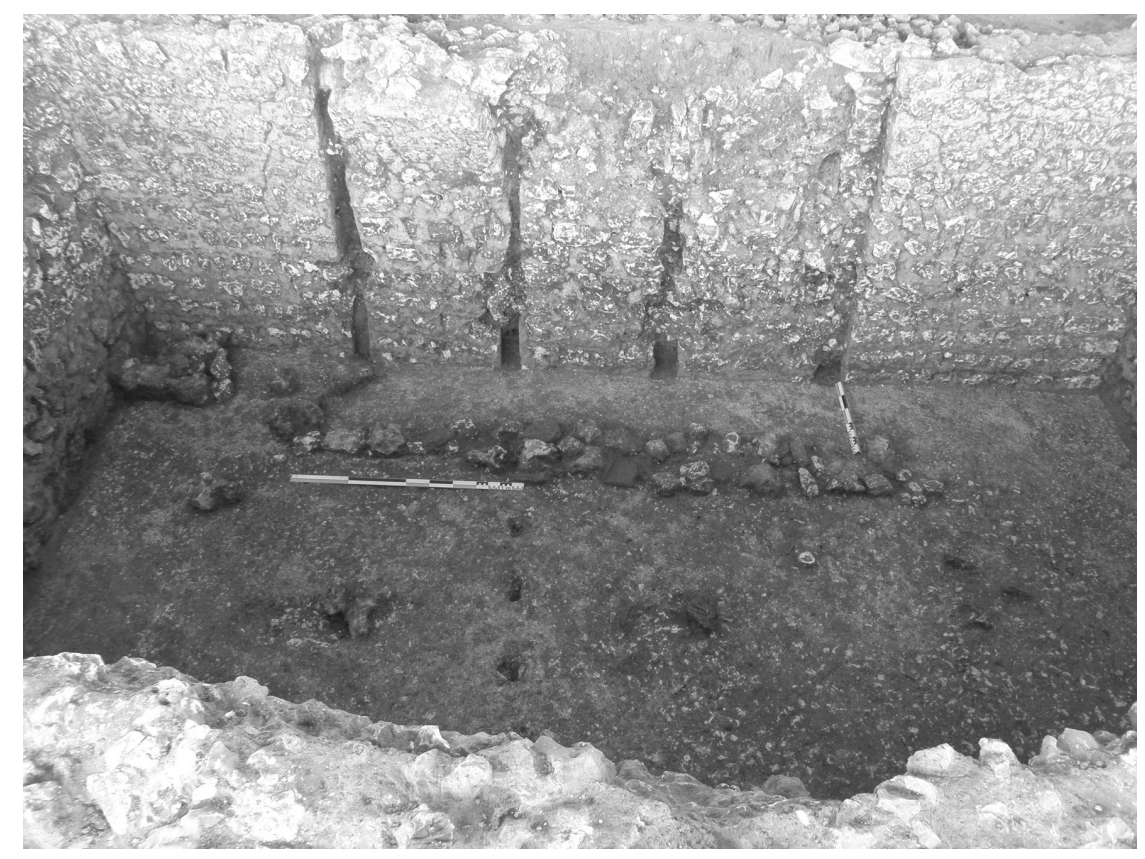

Figure 20 : Aménagements intérieurs de la cave d'Isneauville (Y.-M. Adrian).

Figure 20: Internal structures of the Isneauville cellar.

Figure 21 : Plan de la cave antique de Val-de-Reuil « la Cerisaie».

Figure 21: Plan of the Roman cellar at Val-de-Reuil "la Cerisaie".

emplacement des limons d'escalier

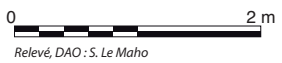

dans le premier comblement de la cave (Seignac, in Beurion (dir.), 2012, p. 341), a prouvé qu'il ne s'agissait pas des vestiges carbonisés d'un plancher ou d'une charpente qui se seraient écroulés (us 3, fig. 25). L'analyse révèle la présence d'essences variées (chêne caducifolié, noisetier, hêtre, pru- nus, érable) qui sont d'excellents combustibles et il est probable que ce dépôt charbonneux soit les restes de vidange d'un foyer (utilisation de petites branches, traces d'insectes xylophages soulignant l'exploitation de bois mort). Ainsi, toutes les couches stratigraphiques rencontrées dans la cave 


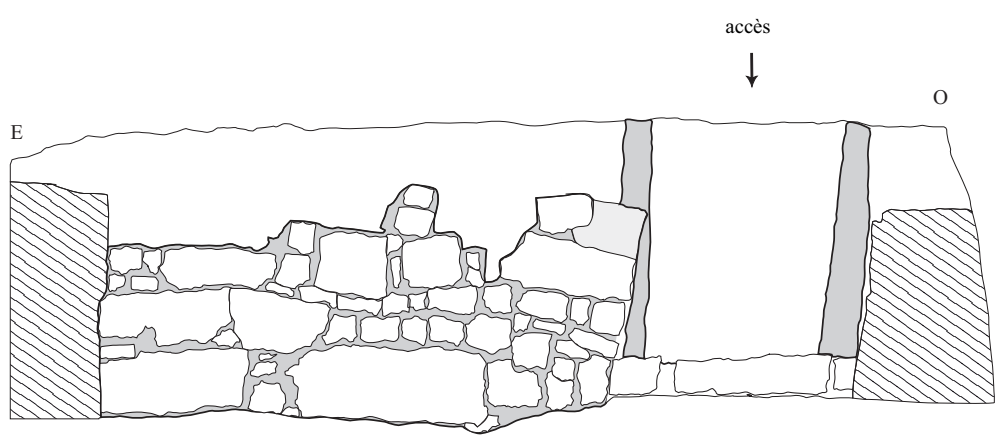

mur sud avec le débouché de l'escalier

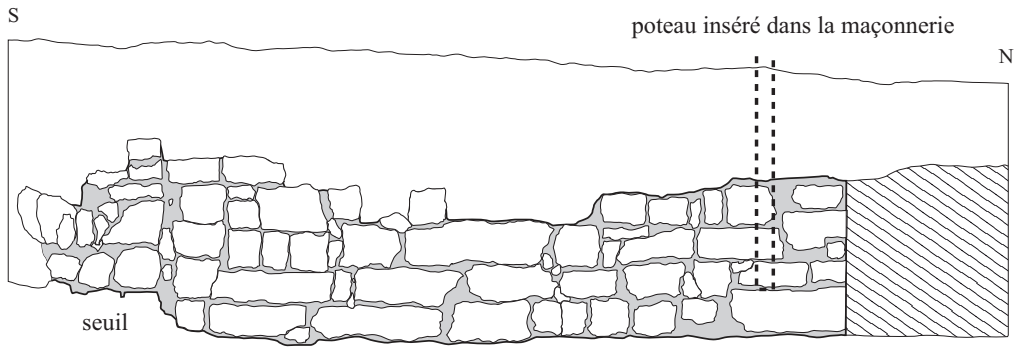

mur ouest

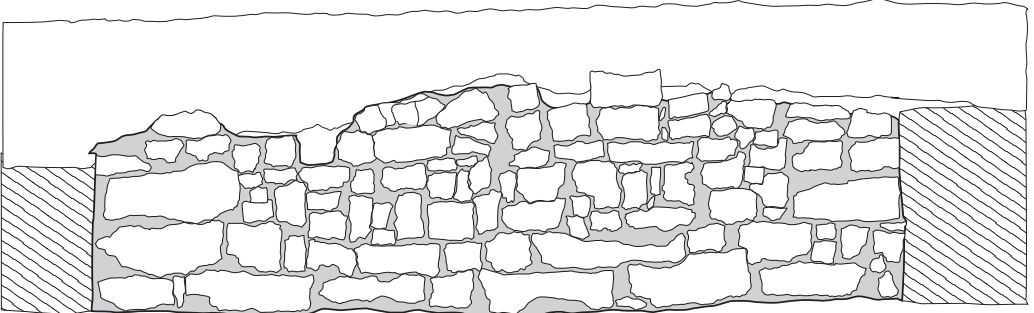

mur nord

Figure 22 : Élévations de la cave de Val-de-

Reuil « la Cerisaie».

Figure 22: Elevation of the Val-de-Reuil "la Cerisaie" cellar.

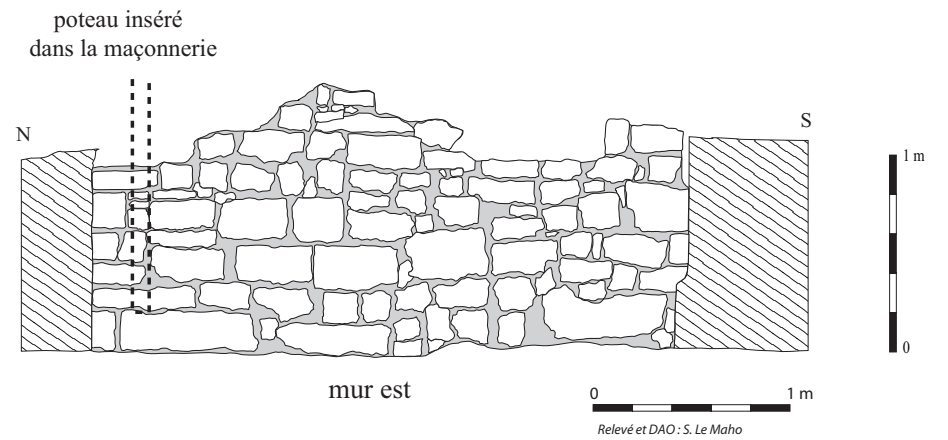

se rapportent exclusivement à des terres rapportées volontairement pour son colmatage, intervenant au $\mathrm{III}^{\mathrm{e}}$ siècle. Le mobilier abondant révèle que le remblaiement s'est fait de manière extrêmement rapide à partir d'un important dépotoir constitué auparavant. En effet, de nombreux remontages de céramiques effectués entre les couches inférieures (us 3 et 4) et supérieures (us 1 et 2) montrent que tout ce matériel constitue un seul et même ensemble détritique dispersé dans les différents niveaux de comblement.

\section{La cave de Val-de-Reuil, Le Chemin aux Errants}

Il s'agit d'une petite construction de 2,56 x 3,88 mètres en dimensions extérieures et 2,80 x 1,66 mètre en dimensions 


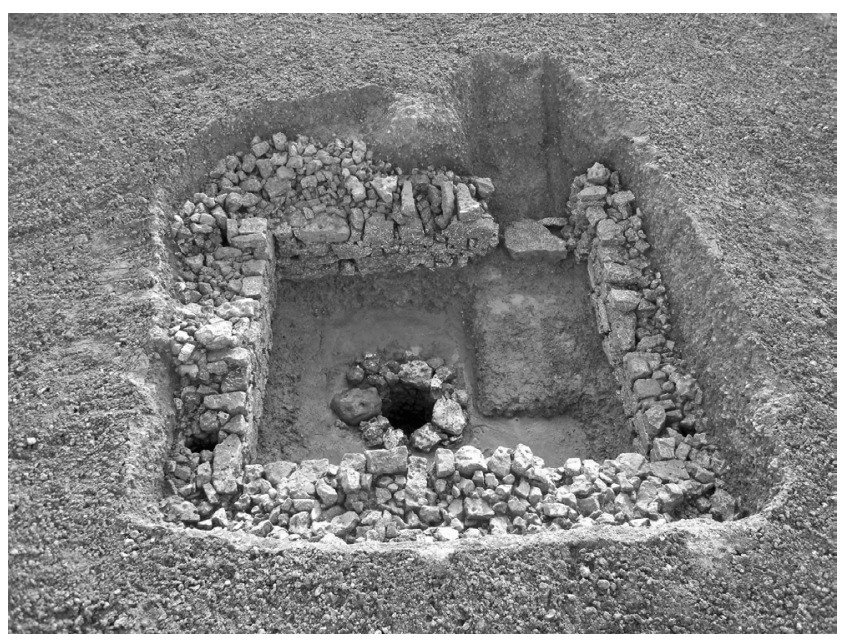

Figure 23 : La cave de Val-de-Reuil « la Cerisaie»(C. Beurion). Figure 23: The Val-de-Reuil "la Cerisaie" cellar and well.

intérieures, soit à peine 4 mètres carrés de superficie interne, réalisée à l'aide de rognons de silex sommairement équarris et facettés, montés en assises régulières avec un mortier orangé (fig. 26 à 29). Les murs ont une épaisseur à peu près constante de $0,50 \mathrm{~m}$, sauf le mur nord fermant la cage d'escalier qui mesure entre 0,30 et 0,40 mètre de large. L'ensemble est conservé sur une hauteur d'environ 1,55 mètre, excepté le pignon nord initial, très détérioré. Deux murs possèdent des petites niches larges de 0,40 mètre, disposées à 1,10 mètre de hauteur : une sur le mur sud, en face de la porte d'accès, et deux sur le mur est. L'encadrement de ces niches est défini par des moellons calcaires. Le fond de l'un de ces aménagements présente une paroi verticale lutée directement contre le terrain naturel, tandis que des traces d'une paroi similaire étaient visibles sur une autre niche (fig. 27 et 30). Bien que très abîmée lors de la démolition de l'édifice, la partie nord de la cave révèle l'emplacement d'une porte matérialisée par les restes du cadre sur lequel les traces d'un chambranle en bois étaient imprimées dans le mortier (fig. 31). Cet encadrement de porte assez large (de l'ordre de 1,10 m) semble par ailleurs avoir été solidaire d'une épaisse pièce de seuil en bois, dont l'emplacement était ménagé dans la maçonnerie (fig. 27).

Cette cave révèle deux états caractérisés uniquement par une réfection ou une amélioration de l'accès extérieur : dans un premier temps, ce dernier semble s'être effectué par l'intermédiaire d'un simple creusement (quadrangulaire?) accolé à la partie nord de la construction, là où se trouvait déjà la porte de la cave. Dépourvu de maçonnerie, cet accès était sans doute associé à un escalier en bois. Après de probables effondrements des parois du substrat friable (sable et grave), une maçonnerie grossière de silex et de mortier beige

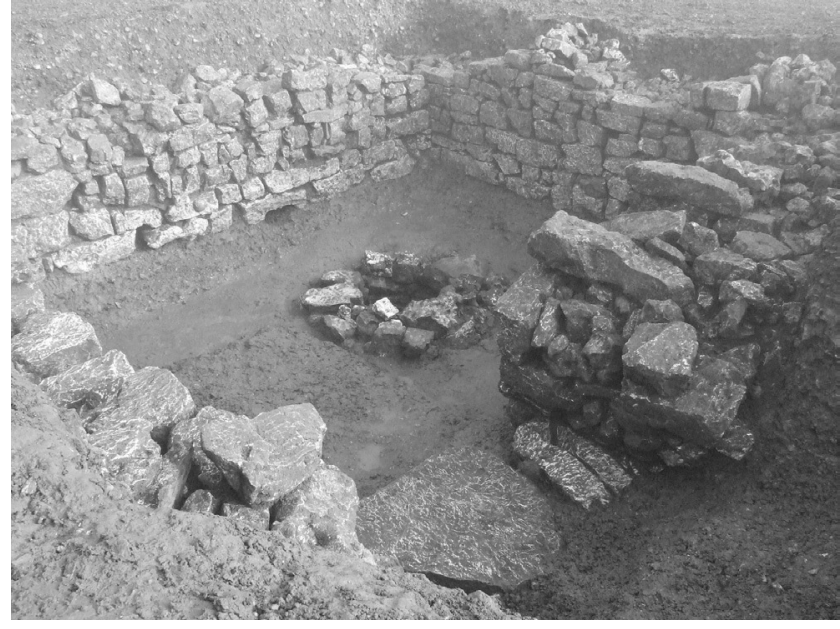

Figure 24 : Vue intérieure de la cave de " la Cerisaie » (Val-deReuil) (C. Beurion).

Figure 24 : Inside view of the "la Cerisaie" (Val-de-Reuil) cellar.

va être plaquée contre les parois nord et est. Cette maçonnerie vient s'appuyer contre l'angle existant de la cave, juste à côté de l'encadrement de la porte (fig. 26). Il est possible que cette amélioration de l'accès aille de pair avec la modification voire la réalisation d'une petite toiture sur auvent. La présence de celle-ci est notamment suggérée par l'absence d'effondrement de paroi ou bien de ruissellement accumulé au fond du creusement, en particulier à l'emplacement de l'escalier en bois, montrant que cette partie de l'édifice était, elle aussi, protégée des intempéries.

Au fond de la cave, un sol lisse, épais de quelques centimètres, réalisé dans le même mortier orangé que les murs, reposait sur un remblai mêlant du mortier plus ou moins solidifié avec des blocs et éclats de silex, probablement issu du chantier de construction (us 25 et 26, fig. 32). La surface centrale de ce sol en mortier était altérée et décolorée par le feu sur environ deux mètres carrés, sans que l'on puisse dire si cette dégradation est liée à l'occupation de la cave (activité ponctuelle ou accident?) ou bien à son abandon. Son caractère localisé et l'absence de dommages sur les murs permettent quoi qu'il en soit d'écarter l'hypothèse d'un incendie.

Cette cave a été remblayée après récupération partielle de certains éléments, dont en premier lieu la porte et son encadrement qui ont manifestement été descellés et arrachés, et ceci sans doute après démontage des élévations (fig. 33). En tout cas, la plupart des remblais accumulés dans la pièce se sont avérés pauvres en matériau de démolition et en mobilier, plusieurs couches étant même complètement stériles. Le mobilier céramique permet toutefois de montrer que la majeure partie de la cave est comblée durant la deuxième moitié du $\mathrm{I}^{\mathrm{er}}$ siècle, tandis que son niveau supérieur ne sera définitivement obturé qu’au $\mathrm{II}^{\mathrm{e}}$ siècle. 


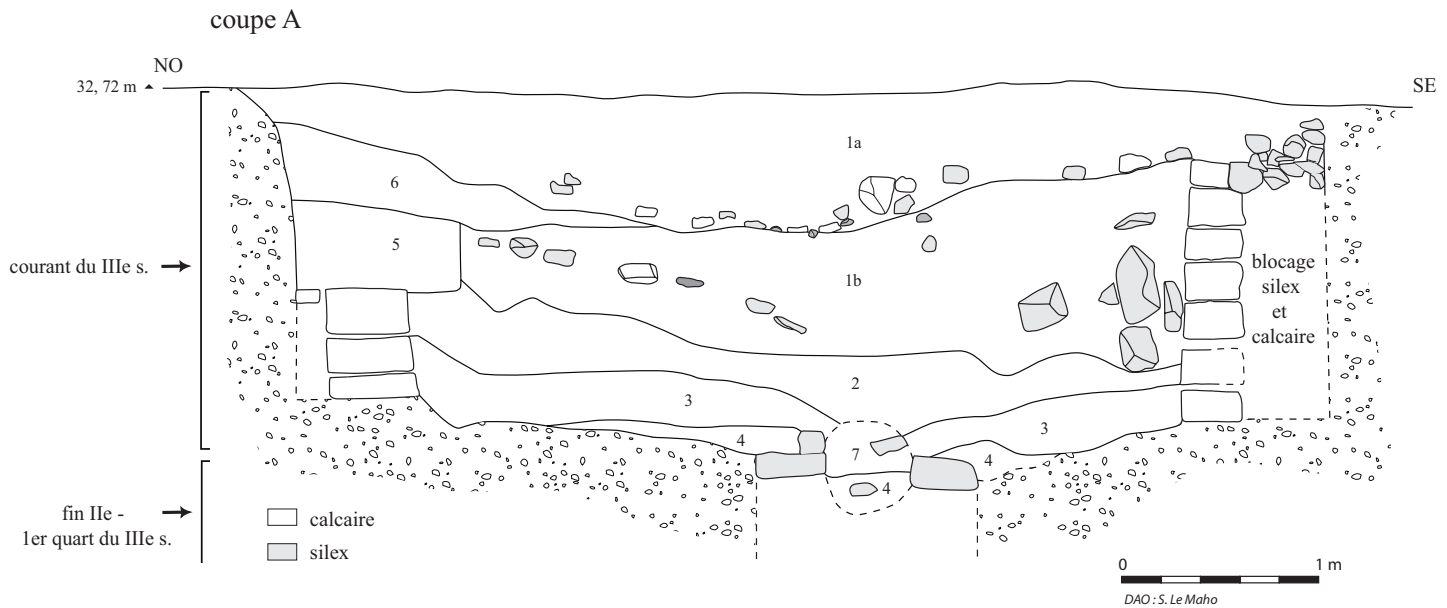

1a : limon argileux brun, blocs de silex, gros et petits blocs de calcaire, inclusions de terre cuite et de calcaire

$1 \mathrm{~b}$ : limon argileux brun foncé, blocs de silex et de calcaire, inclusions de terre cuite, charbons de bois

2 : limon argileux beige , beaucoup de petits blocs de silex et de gros blocs de calcaire, inclusions de calcaire

3 : limon argileux brun foncé, litages discontinus de dépôts charbonneux, petites inclusions de calcaire, quelques blocs de silex et de calcaire
4 : limon beige foncé légèrement sableux, quelques nodules de silex 5 : tranchée de récupération du mur ouest : limon beige avec petits blocs de calcaire et de silex, inclusions de terre cuite et de calcaire

6 : limon beige riche en blocs de grave (effondrement de la paroi), petits blocs et nodules de calcaire

7 : sous-tirage des US 2 et 3 dans la cuve

$\therefore$.

coupe B
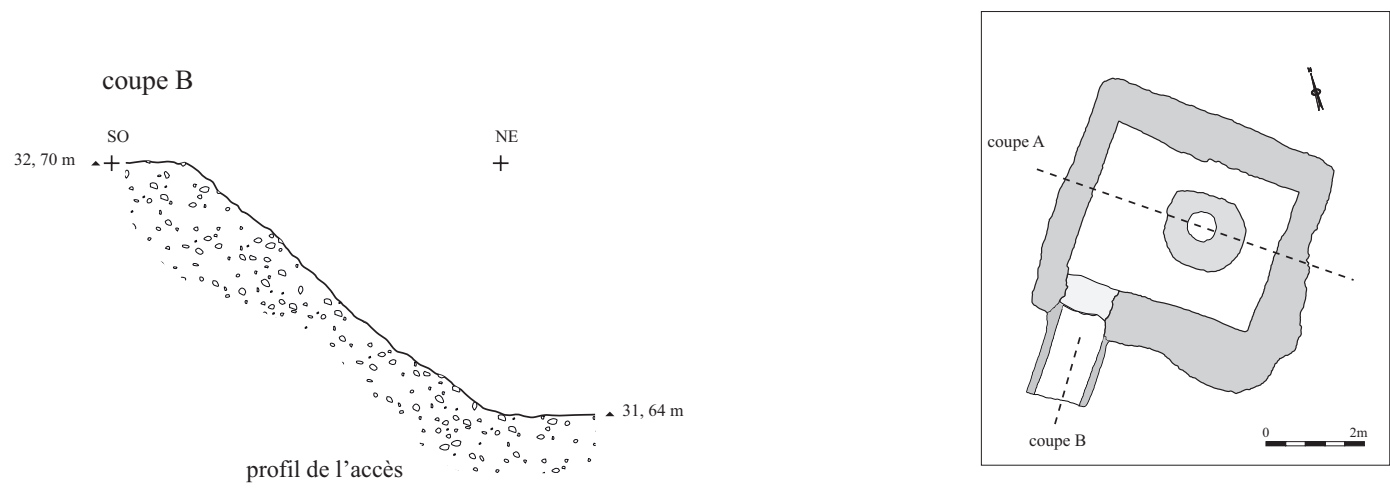

Figure 25 : Coupe stratigraphique et profil de la cave de Val-de-Reuil « la Cerisaie ».

Figure 25: Stratigraphical section of the Val-de-Reuil "la Cerisaie" cellar.

\section{4. ÉTUDE COMPARATIVE}

Les quatre caves présentent chacune plusieurs particularités, aussi bien au niveau de leur emplacement au sein des occupations concernées que de leur architecture, traduisant sans aucun doute des choix différents de la part de leurs commanditaires, comme probablement de leurs constructeurs. De même, leurs fonctions semblent variées mais restent toutefois mal définies, faute d'indice tangible.

\section{Configuration et emplacement}

L'emplacement de ces caves par rapport au réseau fossoyé ou aux autres bâtiments, constitue un premier élément significatif pour appréhender l'organisation des exploitations agricoles et leurs activités. Ainsi, seule celle d'Isneauville est intégrée à un bâtiment plus vaste formant l'habitation. Elle y constitue une annexe, enterrée à l'intérieur d'une vaste pièce allongée servant peut-être de réserve 


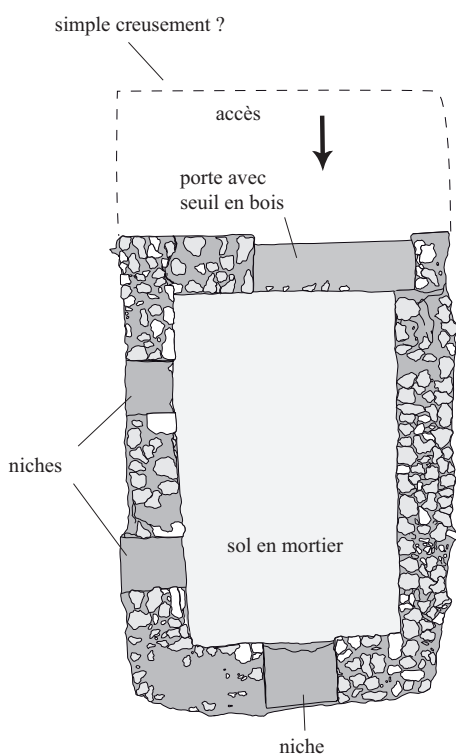

état initial

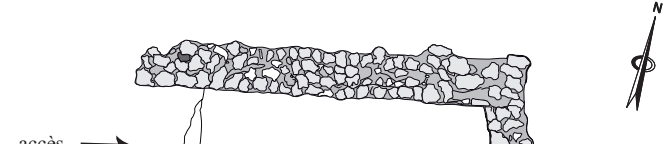

hes

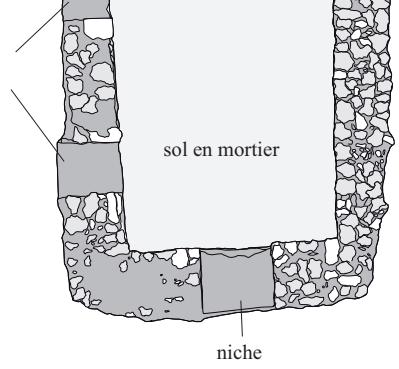

état ultime
Figure 26 : Les deux états de la cave de Val-de-Reuil « Chemin aux Errants ".

Figure 26: The two phases of the Val-de-Reuil "Chemin aux Errants" cellar. et de cuisine, probablement pourvue d'un accès sur l'arrière du bâtiment. À l'inverse, les trois autres caves apparaissent comme des constructions indépendantes plus ou moins isolées, quoique leur relation avec le noyau bâti varie sensiblement. En effet, celle de Parville fait partie du cœur de l'habitat vers lequel elle est en outre tournée, tandis que celles du Chemin aux Errants et de La Cerisaie, à Val-deReuil, en sont clairement détachées. À Parville, la cave se trouve à seulement 17 mètres des différentes constructions formant le noyau résidentiel, tandis que celle du Chemin aux Errants est distante de presque 75 mètres du bâtiment principal. Par ailleurs, cet éloignement se couple ici à un décalage chronologique puisqu'elle est comblée avant que le grand bâtiment d'habitation ne soit construit. Reste que, dans tous les cas, cette petite cave de Val-de-Reuil paraît sensiblement isolée, dans la mesure où les bâtiments voisins semblent également avoir été construits ultérieurement. L'éloignement de l'espace résidentiel est plus manifeste encore à Val-de-Reuil, La Cerisaie où la cave se trouve seule au milieu de parcelles agricoles, juste couplée à un puits à eau. Il est assuré, par les multiples opérations de diagnostic, qu'aucune occupation gallo-romaine d'importance n'est présente sur la haute terrasse dans un rayon de plusieurs centaines de mètres. Au plus près, l'habitat antique pourrait être placé à une centaine de mètres en contrebas, sur la moyenne terrasse. La construction peut donc être rangée dans la catégorie des annexes agricoles, établies en plein champ, dont l'emplacement répond à un besoin spécifique qui n'a aucun lien avec le fonctionnement quotidien de l'habitat, en complète opposition avec les caves de Parville et surtout d'Isneauville.

\section{Des fonctions sans doute diverses}

Si le stockage est spontanément associé au terme même de cave, force est de constater que cette fonction reste ici peu affirmée, faute de preuves tangibles. L'exemple de Valde-Reuil, La Cerisaie est assez particulier en raison de la présence d'une cuve placée pratiquement au centre de la pièce enterrée. Il est certain, rappelons le, qu'il ne s'agit pas d'un puits à eau mais il est difficile de trancher sur la fonction de cet aménagement, destiné de toute évidence à une activité particulière qui reste malheureusement insaisissable. Une quelconque vocation artisanale ne peut être formellement exclue, mais dans la mesure où la cuve se trouve dans un petit bâtiment agricole isolé en plein champ, l'on peut imaginer qu'elle faisait plutôt office de citerne pour la conservation ou la transformation des produits de l'agriculture. Ceci dit, l'absence apparente de dispositif d'étanchéité sur le fond du conduit, tout comme la légère pente ménagée sur le sol en direction de la cuve, pourraient faire pencher pour un puisard - ou puits perdu - drainant des excédents de liquide. D'un autre côté, on peut aussi se demander s'il n'y a pas un lien à établir entre la fosse centrale et les deux 


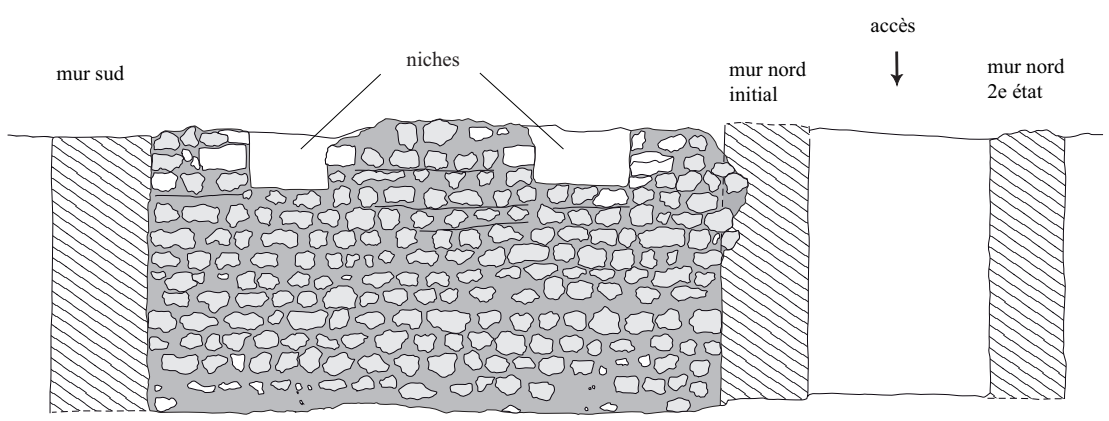

mur ouest (état ultime)

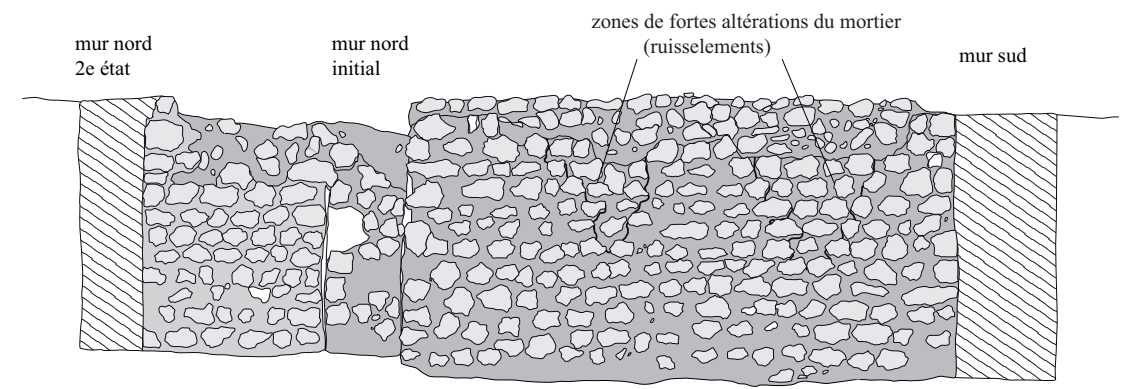

mur est (état ultime)

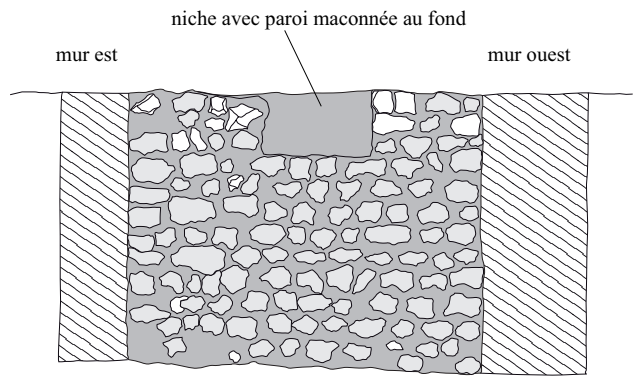

mur sud

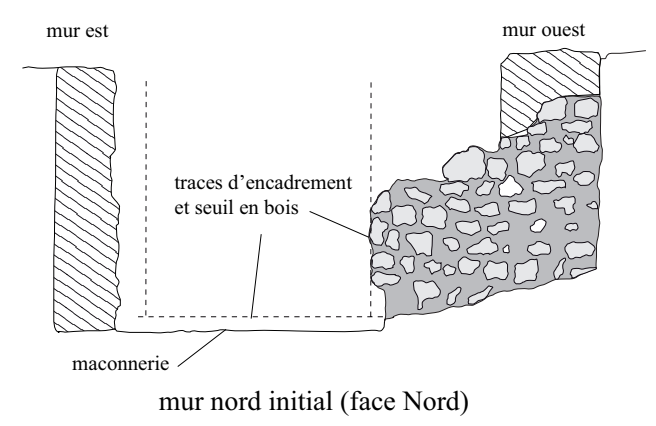

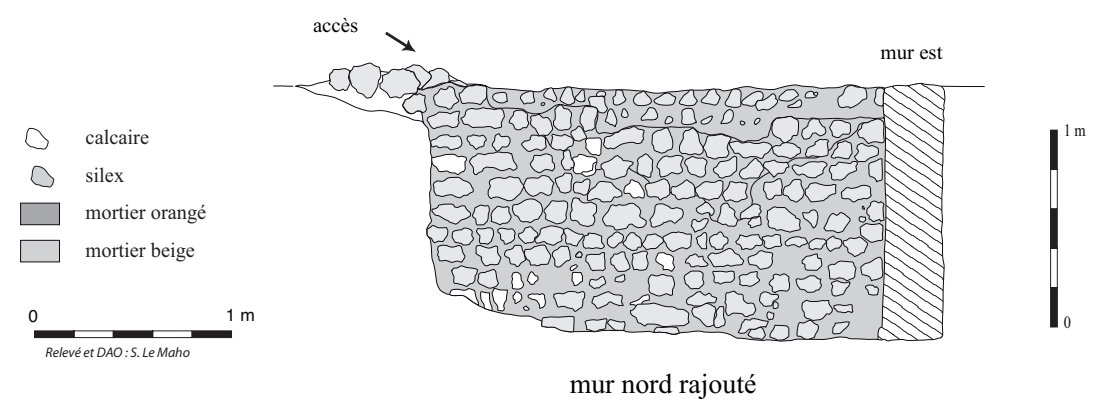

Figure 27 : Élévations de la cave de Val-de-Reuil "Chemin aux Errants".

Figure 27: Elevation of the Val-de-Reuil "Chemin aux Errants" cellar. 


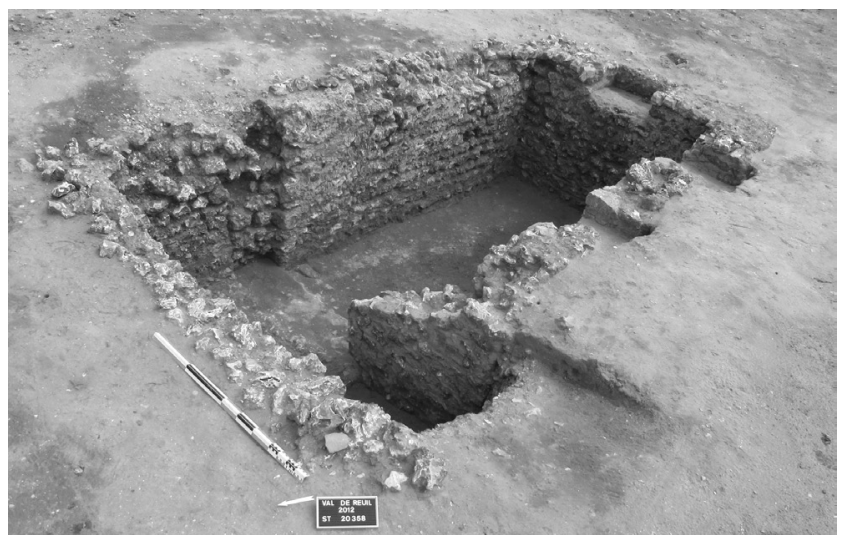

Figure 28 : Vue vers l'est de la cave de Val-de-Reuil « Chemin aux Errants " avec son accès en avant-plan (D. Delafoy).

Figure 28: View to the East of the Val-de-Reuil "Chemin aux Errants" cellar with its entrance in the foreground.

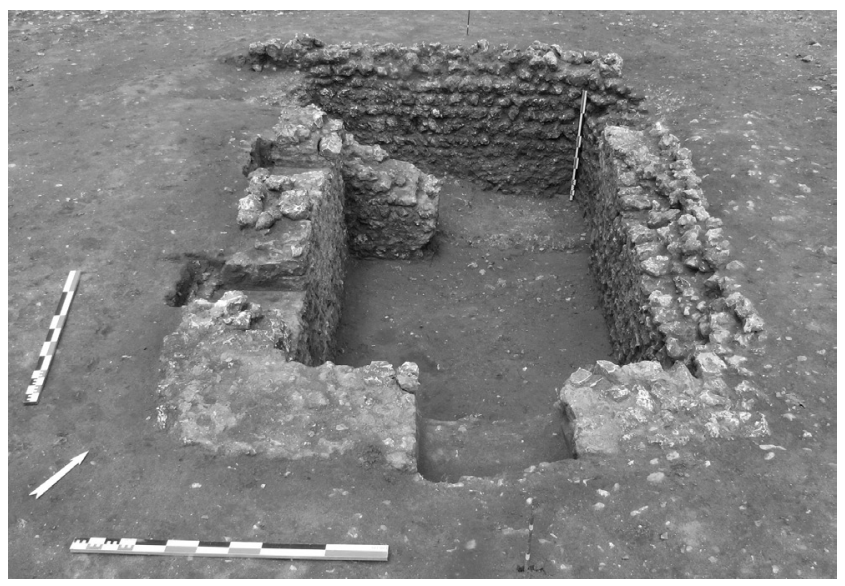

Figure 29 : Vue d'ensemble de la cave de Val de Reuil "Chemin aux Errants" (Y.-M. Adrian).

Figure 29: View of the Val-de-Reuil "Chemin aux Errants" cellar.

poteaux verticaux ancrés dans les murs. Ceux-ci pourraient correspondre à des soutiens d'une poutre horizontale (système de presse, de suspension ou autre?), la cuve étant alors destinée à recueillir le produit de la transformation ou à accueillir une partie du mécanisme. En dernier lieu, on ne peut exclure qu'elle ait tout simplement servi de réservoir à eau ou de cuve de rafraîchissement.

Pour les trois autres caves, la situation est tout autre dans la mesure où les pièces sont vides et leur sols souvent lisses. En effet, en dehors de la petite cloison aménagée d'abord en travers de la cave d'Isneauville, évoquant l'existence initiale d'un vaste bac ou compartiment de stockage réalisé à même le sol, aucune trace d'aménagement spécifique ne vient témoigner de la fonction de ces différentes pièces. À l'inverse de nombreux exemples connus en Gaule, notamment

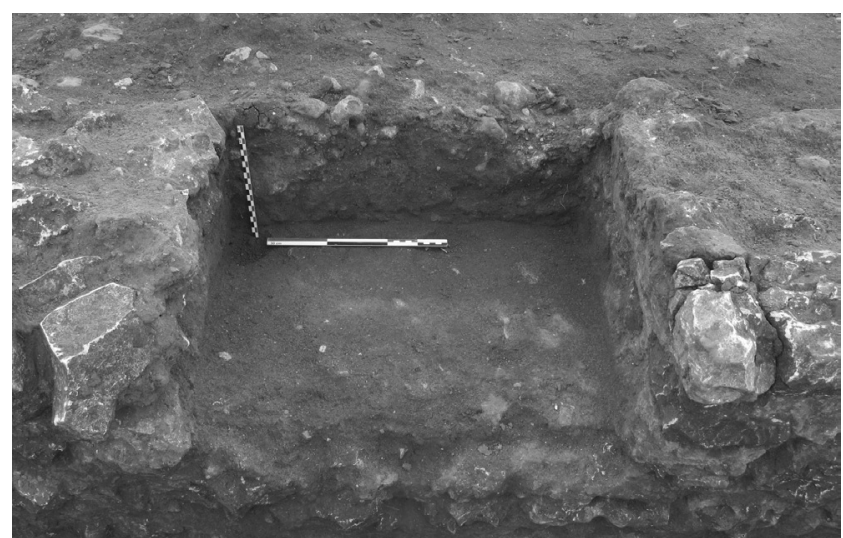

Figure 30 : Niche méridionale de la cave de Val-de-Reuil « Chemin aux Errants " (D. Delafoy).

Figure 30: Southern niche of the Val-de-Reuil "Chemin aux Errants" cellar.

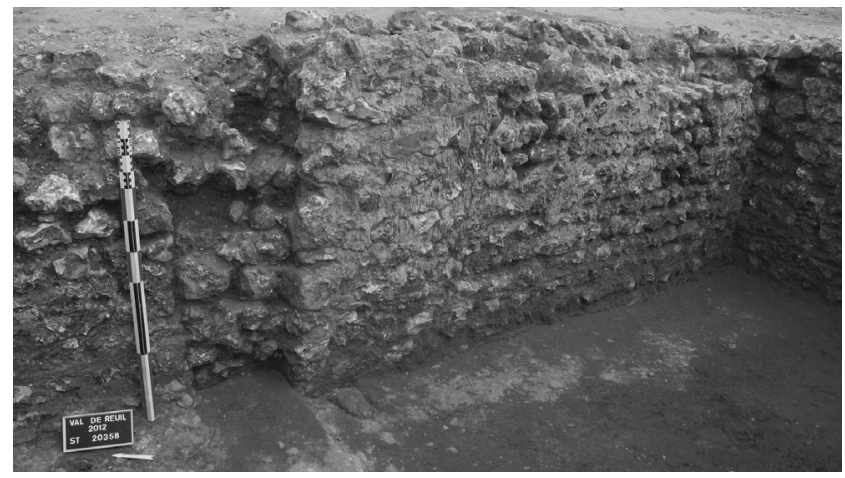

Figure 31: Détail de l'élévation de la cave du "Chemin aux Errants » à Val-de-Reuil (Y.-M. Adrian).

Figure 31 : Detail of the elevation of the Val-de-Reuil "Chemin aux Errants" cellar.

en Île-de-France (Poyeton et al., 2003), aucun logement à amphore/dolia n'a été creusé dans le sol, le long des murs, et si le stockage d'amphores peut tout de même être évoqué, il a dû concerner uniquement des amphores gauloises pourvues de pieds, pour lesquels la réalisation de cupules n'était pas nécessaire. C'était peut-être le cas à Isneauville, dont le sol révèle une forte usure dans la moitié est, dans l'axe de l'escalier alors que la partie ouest montre un sol intact car manifestement en permanence occupé par des objets ou des produits disposés dans le renfoncement de la pièce, le long du mur. À ce sujet, il faut noter que les macro-restes piégés dans le niveau de terre battue recouvrant la pièce révèlent des denrées variées puisqu'ils associent des graines de blé à des restes de poissons et de volatiles. Un stockage d'aliments en amphores et en contenants périssables sur 


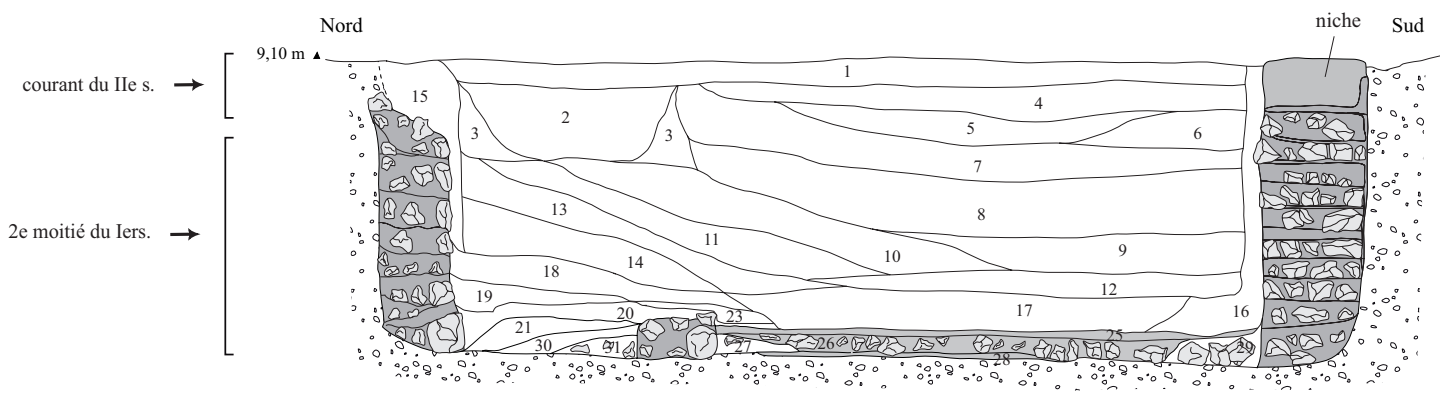

us 1 : remblai sabloneux brun foncé, presque stérile (qq tessons du IIe s.)

us 2 : remblai stérile de sable brun avec grave (= creusement contemporain)

Relevé, DAO:D. Delafoy

us 3 : remblai sableux brun foncé (= creusement contemporain ?)

us $4:$ remblai sablonneux brun clair avec mobilier erratique du IIe s.

us 5 : remblai sabloneux gris clair, compact

us 6 : couche stérile de sable et de grave

us 7 : remblai de sable brun avec éclats de silex et débris de mortier orangé

us 8 : remblai de sable brun avec faible densité de grave ; mobilier céramique du Ier s.

us 9 : remblai de sable brun fonçé avec forte densité de grave

us 10 : remblai de sable brun fonçé avec très forte densité de grave et faible mobilier céramique du Ier s.

us 11 : remblai de sable brun avec débris épars dont des nodules de mortier orangé

us 12 : couche de sable noirâtre avec nodules de calcaire et mobilier céramique du Ier s.

us 13 : remblai de sable brun fonçé avec forte densité de grave

us 14 : remblai de sable noirâtre avec faible densité de grave

us 15 et 16 : couches de sable et fins gravillons (infiltrations et ruissellements)

us 17 : remblai de sable brun noir, avec blocs de grave épars et mobilier céramique du Ier s.

us 18 : couche de sable brun, riche en débris de calcaire, éclats de silex et blocs de mortier

us 19 : couche de sable brun riche en silex et débris de mortier

us 20 : couche mélant éclats de mortier et débris de calcaire

us 21 : mortier orangé avec silex et éclats calcaires

us 23 : couche de mortier beige pulvérulent

us 25 : sol en mortier orangé, altéré en son centre par une combustion et couvert d'une fine couche charbonneuse

us 26 : couche de mortier et de gros blocs de silex (niveau de prépration de sol 25)

us $27:$ débris de mortier pulvérulent

us 28 : niveau de craie pulvérulente

us $29:$ rognons de silex alignés

us $30:$ débris de mortier pulvérulent

us $31:$ mortier orangé fin et régulier

$\because \quad$ terrain naturel (grave de silex et sable)

mortier orangé avec silex et éclats calcaires

Figure 32 : Coupe stratigraphique longitudinale de la cave de Val-de-Reuil "Chemin aux Errants ». Figure 32: Longitudinal stratigraphical section of the Val-de-Reuil "Chemin aux Errants" cellar.

Figure 33 : La cave de Val-de-Reuil « Chemin aux Errants » en cours de fouille (D. Delafoy). Figure 33: The Val-de-Reuil "Chemin aux Errants" cellar during excavation.

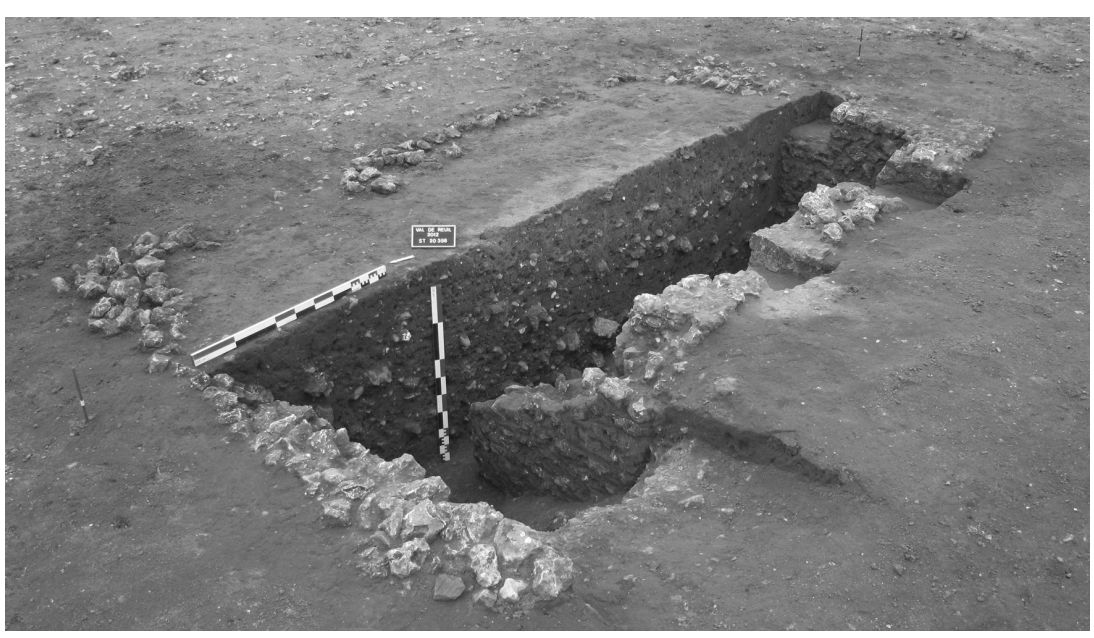


étagères paraît donc plausible, idée par ailleurs confortée par l'emplacement de cette cave à l'intérieur de l'habitation mais à l'arrière, au sein d'une pièce sans doute de service, peut-être une cuisine (?). À Parville, la situation diffère et la cave pourrait avoir servi au stockage de tonneaux dont la présence est avant tout suggérée par l'existence certaine d'un grand pressoir sur le site (Hervé-Monteil et al., 2011). Il s'agirait alors d'un chai. À l'appui de cette hypothèse, il est possible de relever la longueur de l'accès, évoquant l'existence d'un escalier en pente douce, ainsi que sa position dans l'axe de la cave, facilitant les manutentions. Mais a contrario, on pourra s'étonner de la taille somme toute restreinte de l'entrée (0,9 mètre de large) comme de la pièce (seulement 12 mètres carrés) et donc de sa faible capacité de stockage pour des tonneaux à vin.

Quoi qu'il en soit, le stockage de denrées en vrac (grains ou autres produits agricoles semi-finis destinés à l'alimentation) ou conditionnées (en amphores, tonneaux, caisses, paniers, ballots) est donc vraisemblablement la première destination des trois caves, plutôt simples, d'Isneauville, Parville et de Val-de-Reuil, Les Errants, sans exclure un double usage de service, tel un artisanat occasionnel. Il paraît en tout cas évident que des caves indépendantes, et parfois quelque peu séparées du noyau principal de l'habitat comme celle de Valde-Reuil, Les Errants, n'ont pas été destinées aux mêmes usages que des caves intégrées dans un bâtiment d'habitation comme celle d'Isneauville ou faisant partie du noyau d'habitat comme celle de Parville.

\section{Des constructions variées}

L'impression de variété dégagée par ces quatre caves s'exprime encore plus fortement sur le plan architectural (fig. 34 et tableau 1). En effet, aucune de ces constructions ne se ressemble, tant dans le choix et/ou la combinaison des matériaux que dans leur mise en ouvre. De même, leur plan diffère. L'une d'elles est pratiquement carrée tandis que les trois autres sont rectangulaires, mais selon un rapport longueur/largeur plus ou moins prononcé. Ainsi, la cave de Parville forme un rectangle large $(5 \times 4,50 \mathrm{~m})$ tandis que celles d'Isneauville et de Val-de-Reuil, Le Chemin aux Errants, sont beaucoup plus étroites (respectivement 2,70 x 4,65 mètres et 2,56 x 3,88 mètres). À Val-de-Reuil, La Cerisaie, seule une différence de 0,50 mètre la sépare du carré.

Le choix des matériaux utilisés répond logiquement aux disponibilités locales et sans doute aussi à la proximité de carrières. C'est donc sans surprise que la craie du Secondaire et le silex ont été systématiquement utilisés. À Parville comme à Isneauville, l'utilisation conjointe de ces deux pierres correspond aussi bien à des choix pratiques qu'économiques puisqu'il s'agit de matériaux facilement disponibles dans l'environnement proche des sites, notamment à la faveur des reliefs marquant les rebords de plateaux sur lesquels ces deux habitats sont installés. Même si elles n'intègrent chacune qu'un seul type de matériau dans leur parement, les deux caves de Val-de-Reuil participent à ce même type de démarche rationnelle, qui trouve bien entendu tout son sens pour des constructions aussi modestes qu'utilitaires.

Toutefois, l'emploi parfois couplé de ces matériaux locaux n'explique évidemment pas la diversité architecturale de ces caves. Ainsi, à Parville, des moellons calcaires rectangulaires bien taillés sont mis en œuvre dans certaines parties de la construction, que ce soit au niveau des angles des murs ou de l'encadrement des ouvertures (porte et niches ou soupiraux). Associé au jointoiement soigné au fer de ces moellons, cet appareillage mixte crée un effet visuel manifeste. Néanmoins, ce dernier n'a évidemment rien de commun avec la qualité architecturale de certaines caves comportant des appareillages réticulés et polychromes, comme celle exhumée à Famars, près de Valenciennes (Clotuche, 2013). À Isneauville, une certaine recherche esthétique complète sans doute la volonté de solidité et d'efficacité de la construction qui associe un soubassement de silex sur quatre assises, des pierres résistantes et sèches, à une paroi de moellons calcaires dont l'irrégularité de la taille a été atténuée par le jointoiement au mortier. Si le mur rajouté a posteriori du côté ouest n'intègre pas de silex comme les autres, le constructeur a tout de même pris le soin d'utiliser deux mortiers de chaux différents : un mortier rouge orangé, aux propriétés probablement plus hydrauliques car intégrant un peu de tuileau, dans la partie inférieure et un mortier beige classique dans la partie supérieure (fig. 17 et 18). En comparaison, les deux caves de Val-de-Reuil apparaissent comme des constructions nettement moins élaborées. Au Chemin aux Errants, la taille des pierres aussi bien que leurs assises se révèlent assez approximatives, bien que l'irrégularité ait été en partie compensée lors de la mise en œuvre du mortier. Quant à la cave de La Cerisaie, complètement différente des trois autres, elle montre un appareillage incertain (Ginouvès, Martin, 1985) et sommairement parementé, constitué de pierres de différentes dimensions et montées à sec. Par ailleurs, la mise en œuvre d'une maçonnerie rustique se couple ici avec une technique tout à fait originale de poteaux pris dans les maçonneries de la cave, et qui pose un peu question. En effet, si l'ancrage de poteaux verticaux dans l'épaisseur des murs peut s'expliquer par une volonté de solidariser la partie enterrée à la partie haute du bâtiment, entièrement en bois, la profondeur de ces supports étonne puisque ceux-ci descendent jusqu'à la toute première assise de blocs, d'autant qu'ils ne sont que deux, disposés en visà-vis. Les deux autres poteaux qui auraient pu être disposés près des autres angles afin de réaliser une structure porteuse 


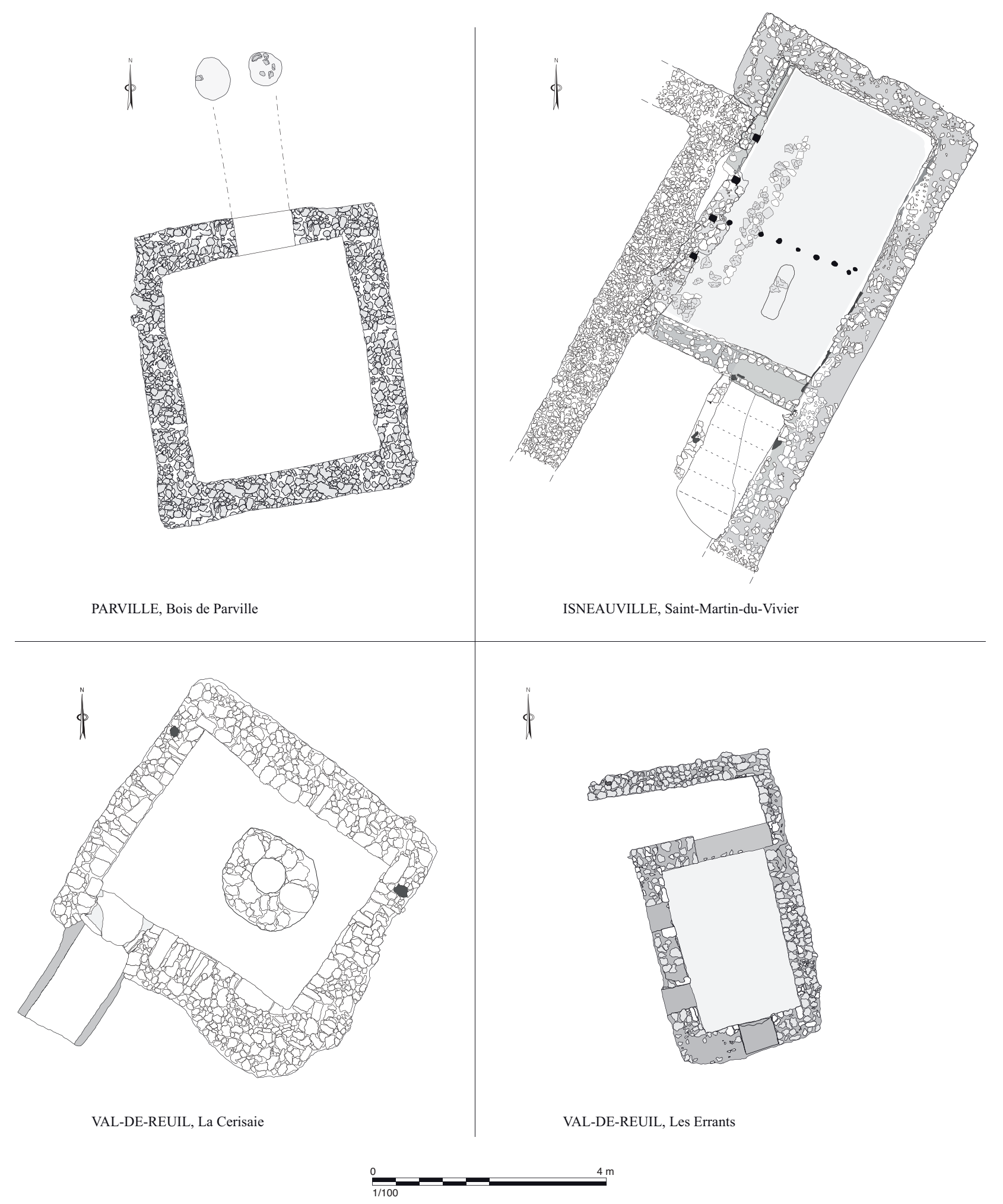

Figure 34 : Planche comparative des quatre caves gallo-romaines étudiées. Figure 34: Comparison of the four Roman cellars. 


\begin{tabular}{|c|c|c|c|c|c|}
\hline & dimensions extérieures & dimensions intérieures & hauteur conservée & surface nette & surface brute \\
\hline $\begin{array}{c}\text { Val-de-Reuil, } \\
\text { Les Errants }\end{array}$ & $3,88 \times 2,56$ mètres & $2,80 \times 1,66$ mètre & 1,55 mètre & 4 mètres carrés & $\begin{array}{c}9,90 \text { mètres } \\
\text { carrés }\end{array}$ \\
\hline $\begin{array}{c}\text { Val-de-Reuil, } \\
\text { La Cerisaie }\end{array}$ & $5,50 \times 5$ mètres & $3,90 \times 3,05$ mètres & 1,85 mètre & 12 mètres carrés & $\begin{array}{c}27,50 \text { mètres } \\
\text { carrés }\end{array}$ \\
\hline Parville & $5 \times 4,50$ mètres & $3,70 \times 3,20$ mètres & 2 mètres & 12 mètres carrés & $\begin{array}{c}22,50 \text { mètres } \\
\text { carrés }\end{array}$ \\
\hline Isneauville & $6,45 \times 4,4$ mètres & $4,65 \times 2,70$ mètres & 1,65 mètre & $\begin{array}{c}12,50 \text { mètres } \\
\text { carrés }\end{array}$ & $\begin{array}{c}28,40 \text { mètres } \\
\text { carrés }\end{array}$ \\
\hline
\end{tabular}

Tableau 1 : Tableau récapitulatif des dimensions des caves.

Table 1: Table summarizing the cellars' measurements.

quadrangulaire ne semblent pas exister, du moins à la même profondeur. Dans l'état actuel des données, le système de construction mis en œuvre à Val-de-Reuil, La Cerisaie, reste sans équivalent, ce qui soulève l'hypothèse d'un dispositif de machinerie lié à l'utilisation de la cuve (cf. supra, IV-B).

Le soin apporté à la construction, ainsi qu'éventuellement à la finition de ces caves, est parfois renforcé par l'élaboration de leur sol : s'il est simplement constitué du terrain naturel à Parville et à Val-de-Reuil, La Cerisaie, il s'avère relativement soigné à Isneauville comme à Val-de-Reuil, Le Chemin aux Errants. Mais dans ces deux cas, la technique utilisée diffère : à Isneauville, le sol est formé d'une couche de craie damée de 10 à $15 \mathrm{~cm}$ d'épaisseur recouverte d'un lait de chaux, tandis qu'il est composé d'une couche de mortier lissé à Val-de-Reuil. Si des choix ou opportunités de constructeurs peuvent expliquer ces variantes, il est probable qu'une telle disparité résulte en partie de la fonction même des caves, comme le suggère notamment celle de Val-deReuil, La Cerisaie, où la présence d'un sol naturel pourrait s'expliquer par les problèmes d'humidité générés par l'utilisation de la cuve centrale, qui plus est s'il s'agissait d'un usage intensif dans le cadre d'une éventuelle activité de production. Par contre, l'absence de sol aménagé dans la cave de Parville pose question étant donné le soin évident apporté à sa construction. Le choix d'un sol en terre aurait-il, là aussi, un rapport avec une fonction spécifique?

C'est sans doute au niveau de leur mode d'accès que ces quatre caves sont les plus semblables : toutes ont en effet été pourvues d'un escalier en bois. L'emplacement et la configuration de ce dernier varient néanmoins : à Parville, l'escalier est parfaitement dans l'axe de la cave tandis qu'il est complètement désaxé à Isneauville comme à Val-de-Reuil, La Cerisaie. Il est latéral et peut-être en quart tournant à Valde-Reuil, Le Chemin aux Errants. L'implantation de l'escalier est, de toute évidence, étroitement liée à l'utilisation de la pièce et à son organisation intérieure, mais il faut bien reconnaitre que les indices manquent ici cruellement pour appréhender ces aspects. Car si la cave d'Isneauville révèle l'ancrage d'une cloison légère dans son état initial, celle-ci parât diviser toute la pièce et sa relation avec l'implantation de l'escalier n'est pas évidente. Au contraire, cette cloison semble barrer la circulation. Seule la cave de La Cerisaie possède un aménagement intérieur, en l'occurrence une cuve dont l'implantation a manifestement conditionné la distribution générale de la pièce, notamment celle de son accès. Lorsque les caves correspondent à des constructions indépendantes, l'escalier a probablement fait l'objet d'une couverture mais celle-ci ne se matérialise pas toujours. À Parville, elle est vraisemblablement associée à l'ancrage des deux importants trous de poteau encadrant le haut de l'escalier tandis qu'à Val-de-Reuil, Le Chemin aux Errants, elle a sans doute reposé sur le mur renforçant la cage d'escalier. Par contre, une protection reste plus hypothétique sur le site de La Cerisaie, bien que la nature périssable de l'escalier en bois et sa forte inclinaison laissent imaginer qu'il était lui aussi couvert. L'existence d'un simple auvent appuyé sur la maçonnerie des élévations et supporté par deux étais posés sur le sol est tout aussi envisageable.

La question des soupiraux ou des niches constitue un autre point important de l'architecture de ces caves. Malheureusement, leur état de conservation ne permet pas toujours d'établir avec certitude la présence de l'un ou l'autre de ces deux aménagements, faute d'une hauteur suffisante ou même devant l'importance des récupérations comme à Val-de-Reuil, La Cerisaie. Toutefois, il n'y a pas ici de multiples renfoncements alvéolaires dans les murs comme il en existe un certain nombre d'exemples en Gaule, aménagements d'ailleurs curieusement définis comme niches au même titre que les petits logements de quelques décimètres carrés aménagés à une certaine hauteur des parois. À Parville, seule la partie inférieure de deux petites cavités réalisées dans les murs sud et ouest évoque l'existence de soupiraux, sans exclure la possibilité de niches voire la combinaison des deux comme il en existe de nombreux exemples. Si peu de caves semblent avoir possédé deux soupiraux, le nombre de niches peut par contre fortement varier et atteindre six comme l'at- 
testent entre autres une cave de Rouen (Lequoy, Guillot, 2004, p. 133 et fig. 92) ainsi que celle d'Épretot, en SeineMaritime (Desfossés, 1992). À Val-de-Reuil, Le Chemin aux Errants, trois petites niches ont été aménagées pour l'une, dans le mur sud et pour les deux autres, dans le mur ouest, à une hauteur de 1,10 mètre. Ces cavités traversant l'épaisseur des murs possèdent chacune une surface d'appui parfaitement horizontale tandis qu'au moins deux d'entre elles ont révélé une paroi maçonnée verticale au fond, directement luttée contre le terrain naturel. Outre ces niches, cette cave possédait peut-être deux petits soupiraux dans son mur est, comme le suggèrent deux zones d'altération du mortier en haut des murs, qui sont visiblement à mettre en rapport avec des ruissellements localisés, intervenus depuis le haut de cette partie de la construction (fig. 27 et 31).

\section{Chronologie}

La période de construction de ces quatre caves n'est pas toujours connue avec précision, en l'absence de mobilier associé à leur mise en œuvre (fig. 35). Seules deux d'entre elles sont datées avec une relative fiabilité. C'est le cas de celle de Val-de-Reuil, Le Chemin aux Errants, dont le comblement inférieur est daté du dernier tiers du $\mathrm{I}^{\text {er }}$ siècle, ce qui permet de situer sa construction entre les deuxième et troisième quarts du $\mathrm{I}^{\mathrm{er}}$ siècle. Au regard des données régionales, il est en effet exclu que ce bâtiment soit plus ancien (augustéen), d'autant que les témoins du début du $\mathrm{I}^{\text {er }}$ siècle sont pratiquement absents de ce site. Reste que cette cave de Val-de-Reuil est assurément la plus ancienne des quatre, et vraisemblablement de la région, en particulier dans les campagnes ${ }^{2}$.

La cave d'Isneauville est pourvue d'un élément de datation par le biais de céramiques trouvées dans le comblement de la tranchée de fondation du mur oriental, à l'emplacement de l'escalier. Ce matériel met en évidence une construction peu après le milieu du $\mathrm{II}^{\mathrm{e}}$ siècle. En comparant cette datation avec celle de son remblaiement intervenu à partir du début du $\mathrm{III}^{\mathrm{e}}$ siècle, cette cave révèle donc une durée d'utilisation assez courte de quelques décennies (moins d'un demi-siècle), qui trouve d'ailleurs un écho dans celle de Val-de-Reuil évoquée précédemment.

La construction des deux autres caves, celles de Parville et de Val-de-Reuil, La Cerisaie, n'est qu'indirectement fixée par les éléments mobiliers issus des structures bâties ou fossoyées environnantes, ce qui constitue évidemment un indice moins fiable. Si l'on utilise, avec beaucoup de prudence, ce critère

2. Seules quelques caves du I $\mathrm{I}^{\mathrm{er}}$ siècle sont connues à Rouen, notamment sur le site de la "Rue aux Ours" (Guillot, 2012). de datation, il faudrait alors situer leur édification entre la fin $\mathrm{du}^{\mathrm{er}}$ siècle et la première moitié du II ${ }^{\mathrm{e}}$ siècle. À La Cerisaie, le mobilier présent au fond de la cuve renvoie majoritairement au dernier quart du $\mathrm{II}^{\mathrm{e}}-$ début du $\mathrm{III}^{\mathrm{e}}$ siècle, assorti de résidus de la première moitié du II ${ }^{e}$ siècle, mais il est difficile d'affirmer que ces vestiges correspondent bien à l'utilisation de la structure et donc à l'occupation de l'ensemble.

La datation du comblement des quatre caves ne pose par contre pas de difficultés, étant donné les caractéristiques et, parfois aussi, le volume important de mobilier qu'il recèle. Aucune n'a révélé de niveau d'effondrement ou d'amas de matériaux en place au fond, mettant en évidence pour chacune un démantèlement complet des élévations. À Valde-Reuil, La Cerisaie, celui-ci s'accompagne du démontage d'une partie des murs de la cave elle-même, qui se poursuivra en partie après remblaiement partiel de la pièce, comme en témoigne le creusement d'une tranchée de récupération dans les niveaux de comblement (fig. 25).

À Isneauville, l'abandon de la cave est d'abord marqué par plusieurs rejets de boucherie (carcasses partiellement découpées) accumulés au pied de l'escalier du haut duquel ils ont été manifestement jetés et auxquels se mêle un rat, peut-être piégé au fond de la pièce par les premiers remblais qui y sont ensuite déversés (Bémilli in Adrian, 2011, p. 306-307). Les déchets déversés dans ces caves se trouvent inégalement répartis dans les nombreuses couches de remplissage, dont la mise en place résulte parfois d'une alternance de rejets volontaires et d'éboulements de certaines parties des élévations, comme à Isneauville et Parville. Quant au rythme de rebouchage de ces caves, deux cas de figure s'observent : un comblement intégral en peu de temps et un rebouchage progressif. La cave de Val-de-Reuil, La Cerisaie, entièrement remblayée entre les deuxième et troisième quarts du III $^{\mathrm{e}}$ siècle, constitue le seul exemple d'un colmatage dans un laps de temps assez court. Une fois effectuée la récupération des matériaux de construction, le trou béant a été totalement comblé par un apport volontaire et massif de remblais, nécessairement apportés d'ailleurs si l'on considère l'abondance et de la composition du lot mobilier, mais d'origine commune. De nombreux remontages de céramiques, recueillies en haut et en bas de la séquence stratigraphique, l'attestent clairement. Les trois autres caves ont fait en revanche l'objet d'un rebouchage par étapes s'échelonnant sur plusieurs décennies. En ce qui concerne la plus ancienne, celle de Val-de-Reuil, Le Chemin aux Errants, son comblement s'effectue aux trois quarts durant la seconde moitié du $\mathrm{I}^{\mathrm{er}}$ siècle tandis que son colmatage final n'interviendra qu'au II $^{e}$ siècle (fig. 32). La cave d'Isneauville illustre le même phénomène à travers trois grandes séquences de comblement couvrant plusieurs décennies et allant du début à la seconde moitié du III $^{\mathrm{e}}$ siècle (fig. 19). Trois principales étapes de 


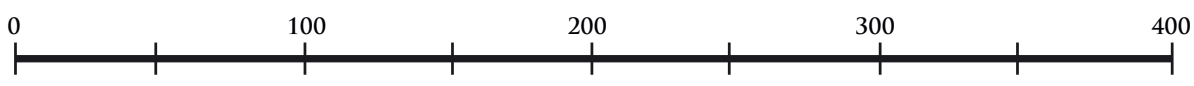

PARVILLE, Bois de Parville

ISNEAUVILLE, Saint Martin-du-Vivier

VAL-DE-REUIL, La Cerisaie

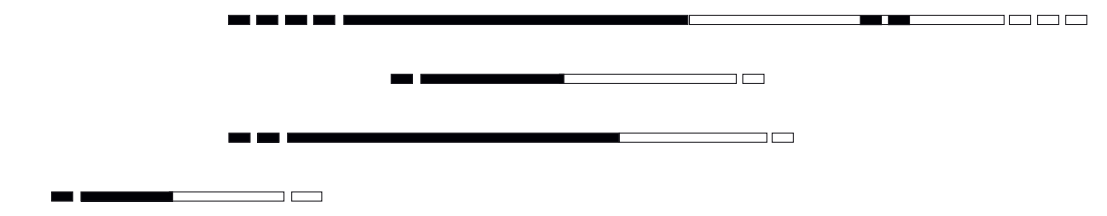

VAL-DE-REUIL, Les Errants

Figure 35 : Diagramme chronologique des quatre caves.

Figure 35: Chronological diagram of the four cellars.

rebouchage, intervenues entre la seconde moitié du $\mathrm{III}^{\mathrm{e}}$ et le courant du Iv siècle, marquent également la cave de Parville (fig. 13). Celle-ci présente toutefois la particularité d'avoir fait l'objet d'une réoccupation ponctuelle dans la première moitié du Iv siècle : quatre niveaux de faible épaisseur, étalés sur des remblais préexistants entre 0,80 mètre et 1,20 mètre au-dessus du sol initial, ont à nouveau permis, pendant un court laps de temps, une circulation au sein de la pièce. Ce rehaussement du sol, entraînant une réduction significative du volume initial du bâtiment, allait probablement de pair avec une modification fonctionnelle : dès lors, cette bâtisse enterrée ne servait sans doute plus d'espace de stockage.

Outre une importante stratigraphie de remblais, les caves de Parville, d'Isneauville et de Val-de-Reuil, La Cerisaie ont chacune livré un ensemble mobilier volumineux et fort varié qui fournit non seulement un important jalon chronologique pour l'abandon des constructions, voire aussi des sites à la fin du Haut-Empire ou bien au début du Bas-Empire, mais donne également un excellent aperçu de la culture matérielle de ces établissements. Ces trois caves recèlent en effet des dépotoirs extrêmement abondants dans lesquels se mêlent de nombreux débris de construction et artefacts en terre cuite, verre, métal et os, relatifs à la vie quotidienne. Outre des lots de faune plus ou moins conséquents, des macro-restes fournissent parfois des informations importantes sur les pratiques alimentaires voire aussi le cheptel. Témoin domestique par excellence, la vaisselle en terre cuite de trois de ces caves représente les ensembles les plus riches de ces sites. Celui de Val-de-Reuil, La Cerisaie, constitue même le lot céramique du III $^{\mathrm{e}}$ siècle le plus remarquable découvert à ce jour en milieu rural dans la région, en raison de son volume (3500 tessons correspondant à près de 200 récipients), de sa composition et de sa qualité de conservation. Les quantités rejetées dans les caves d'Isneauville et de Parville (Adrian, 2011, p. 141 et Lecler-Huby, in Lukas (dir.), 2010, tome II, p. 77) s'avèrent, avec respectivement 1500 et près de 1200 restes, sensiblement inférieures mais représentent tout de même des volumes significatifs au regard de ce qui est généralement découvert en milieu rural. Seule la cave de Val-de-Reuil, Le Chemin aux Errants, ne livre, avec une centaine de tessons mal conservés, qu'un très faible aperçu de la céramique utilisée. Dans trois cas, des verreries (bouteilles, coupes, bols, gobelets et carafes), dont une quarantaine de fragments à Parville et une vingtaine à Val-de-Reuil, La Cerisaie, accompagnent le répertoire de la vaisselle de table ou de service.

Le mobilier métallique peut également être significatif, tant d'un point de vue quantitatif qu'en diversité d'usages et d'informations. Dans les trois cas énumérés précédemment, un grand nombre d'éléments de construction, de quincaillerie et de menuiserie, mais également un outillage varié tel que des faucilles et une serpette (Val-de-Reuil, La Cerisaie, et Parville), relèvent d'activités agricoles ou de domaines divers. La cave de La Cerisaie livre en particulier des objets liés au travail du bois, du fer ou de la pierre, tels que des forets à bois, un grand ciseau et des ciselets (Petit in Beurion (dir.), 2012, p. 287), tandis qu'à Isneauville, deux peignes à carder en fer, deux cloches, une paire de forces ainsi que plusieurs outils ou accessoires, dont une binette et une petite enclume, illustrent des activités agropastorales et artisanales (Leconte in Adrian, 2011, p. 287). Les objets personnels et la parure paraissent à l'inverse moins nombreux dans ces contextes, sans pour autant être négligeables : la cave d'Isneauville a livré deux petites bagues et pions en pâte de verre ainsi qu'une rare fibule en argent d'origine germanique (type Böhme 37), tandis que celle de Val-de-Reuil, La Cerisaie, offre une belle série de vingt-six épingles en os. Le corpus mobilier de la cave de Parville se démarque quant à lui par vingt et une monnaies datées pour l'essentiel entre la seconde moitié du $\mathrm{III}^{\mathrm{e}}$ et la première moitie du $\mathrm{IV}^{\mathrm{e}}$ siècle (Pilon in Lukas [dir.], 2010, tome II, p. 373).

Certains comblements ont aussi livré toutes sortes de matériaux de construction parmi lesquels se distinguent surtout d'abondantes terres cuites architecturales dont l'état 
de conservation s'avère inégal d'un cas à l'autre : elles sont assez bien conservées à Parville mais sont fortement fragmentées voire altérées à Isneauville comme à Val-de-Reuil, La Cerisaie, témoignant d'un démantèlement bien antérieur de la toiture. En outre, ces restes sont inégalement répartis dans les remblais même si une concentration se manifeste par endroits : la cave de Parville s'est ainsi avérée particulièrement riche en terres cuites architecturales dans le niveau inférieur tandis que celle d'Isneauville en a surtout livré dans le colmatage final (fig. 13 et 19). Outre de nombreux débris provenant de l'élévation même des caves, on recense parfois dans les comblements des éléments provenant d'autres bâtiments, comme à Parville où des restes d'enduits peints, de tubulures et briques pour pilettes sont à mettre en relation avec la démolition d'une bâtisse à hypocauste voisine. À Isneauville, une bonne partie des matériaux comblant la cave provient sans doute de la construction elle-même, ce qui est évidemment logique au regard de son emplacement au sein du bâtiment résidentiel : ceci concerne surtout des éboulis de limon encore aggloméré d'un fin enduit à la chaux (us 7 à 10, fig. 19), qui correspond très vraisemblablement aux élévations périssables effondrées après la disparition de la toiture. Cela concerne également des fragments d'enduits peints (blancs et rouges), des briques diverses, dont d'hypocauste, ainsi que des dalles calcaires. Associés aux nombreux fragments de serrureries (pentures, serrures et clés), ces différents matériaux déversés dans au moins deux caves (Parville et Isneauville) fournissent en tous cas de précieux renseignements sur les aménagements intérieurs des bâtiments résidentiels auxquels ces caves sont plus ou moins directement associées et sur lesquels très peu d'informations ont pu être collectées en raison de leur arasement.

\section{Comparaisons}

Quelques autres caves rurales fouillées dans différents secteurs de la région haut-normande fournissent un premier niveau de comparaisons qui peut parfois être élargi aux régions voisines. Quatre constructions enterrées ont ainsi été étudiées, parfois de manière très sommaire à la faveur de découvertes fortuites, à Epretot, Pîtres, Les Damps et EslettesFresquiennes $^{3}$ (fig. 1). Deux d'entre elles sont relativement bien documentées, notamment du point de vue graphique.

3. Une toute nouvelle découverte est à signaler en vallée de la Seine, sur le site de Porte-Joie, Les Vallées (Eure), fouillé à la fin de l'année 2013 (responsable : C. Beurion). Il s'agit d'une cave maçonnée d'une douzaine de mètres carrés de superficie interne, munie d'un accès quart tournant et d'un sol lisse en craie damée, dont les murs ont été presque entièrement récupérés. Là encore, la construction se trouve en position isolée, et manifestement à l'écart de l'ensemble résidentiel.
En intégrant ces découvertes antérieures, il apparaît clairement que les caves, ou plus exactement les petits bâtiments indépendants avec caves, prédominent ce petit corpus régional. Dans ces conditions, celle d'Isneauville est l'une des deux caves implantées à l'intérieur d'un bâtiment plus vaste, et assurément résidentiel. Car la situation de la cave fouillée sur le plateau cauchois à Épretot (Seine-Maritime), (fig. 1), est plus difficile à caractériser, faute de plan complet des maçonneries associées (Desfossés, 1992) : il n'est en effet pas sûr que l'ensemble corresponde à une habitation et on ne peut exclure que la cave fasse partie d'un bâtiment agricole, à l'image de ce qui s'observe sur de nombreuses grandes villae. Cette cave associe en tout cas un sol en craie damée comme celle d'Isneauville, à une maçonnerie rustique de silex montée avec ce qui pourrait être un mortier maigre (limon et un peu de chaux). Son accès illustre un autre modèle d'escalier puisqu'il se compose de quatre marches grossièrement taillées dans le limon naturel et sans doute habillées de planches. Au regard de la petite taille de la pièce, environ 5 mètres carrés, le nombre important de niches (6) peut surprendre d'autant que l'une est large de plus d'un mètre. Fait singulier, la cave de Val-de-Reuil, Le Chemin aux Errants, offre une superficie très modeste elle aussi (moins de 5 mètres carrés) et possède trois niches, ce qui amène à s'interroger sur l'éventualité d'une fonction spécifique pour ces pièces à plusieurs niches. Or des cas similaires de petites caves avec plusieurs niches sont signalés dans la région, à Pîtres (Eure), non loin de Val-de-Reuil, ou bien ailleurs, notamment dans le Val-d'Oise à Beaumontsur-Oise (Wabant et al., 2006, p. 175) ou encore en Vendée, à Jard-sur-Mer, dans des petits bâtiments agricoles d'une grande villa (Séris, 2009). Assez bien documentée par son inventeur L. Coutil, la cave dégagée au XIx ${ }^{e}$ siècle à Pîtres (Eure), près de la Pierre de Saint-Martin, représente une autre variante de petite cave $(2,95 \times 2,70$ mètres, soit moins de 8 mètres carrés) presque carrée et pourvue de niches. Construite en petit appareil avec des joints rectifiés au fer, celle-ci était en effet dotée de deux petites cavités semi-circulaires dans la paroi ouest et d'une large niche rectangulaire dans la paroi nord. Possédant un simple sol en terre battue, elle semble avoir été recouverte par un plancher en bois (Cliquet, 1993, p. 225).

Une autre cave, fouillée non loin de Rouen, à EslettesFresquiennes (Seine-Maritime), représente une variante intéressante de construction rustique isolée (Léon, Adrian, 1997) : de forme presque parfaitement carrée et d'assez grandes dimensions ( 4 × 3,50 mètres intérieurs, soit 14 mètres carrés), elle a été édifiée à l'aide de rognons de silex liés à la terre formant des murs d'environ 0,50 mètre d'épaisseur. Situé au sud-est, sur le côté du mur, son escalier était également en bois assemblé avec des clous découverts in situ. Implantée à l'angle d'une parcelle agricole, cette cave révèle par ailleurs quelques autres informations importantes, 
notamment au sujet de sa toiture en tuiles en grande partie effondrée au fond de la pièce, ce qui constitue un fait unique dans la région. Cet effondrement de la toiture a précédé un remblaiement volontaire très partiel de la cave au cours de la première moitié du $\mathrm{III}^{\mathrm{e}}$ siècle, qui finira par s'effondrer en partie sur elle-même et se colmater naturellement. La découverte d'une colonne et d'un chapiteau en calcaire dans la partie inférieure du comblement laisse à penser que la pièce disposait d'un étai pour le plancher situé au-dessus. Or, ce type d'aménagement est bien attesté dans des caves de Gaule, notamment à Rouen (Seine-Maritime; Lequoy, Guillot, 2004, p. 133) ou bien en Île-de-France comme à Grisy-Coubert (Seine-et-Marne; Renard-Vignais, 1998), pour ne citer que ces exemples. Comme le montre le cas d'Eslettes-Fresquiennes, la présence d'un étai dans la cave n'est pas nécessairement associée à une pièce enterrée de très grandes dimensions, mais doit sans doute s'expliquer par la présence de charges lourdes sur le plancher de la pièce située au dessus.

Dans un autre registre, la technique encore peu connue semble-t-il, utilisée pour renforcer l'une des parois de la cave d'Isneauville, trouve quant à elle un exact parallèle dans une cave étudiée récemment à Dourdan (Essonne) (Magiterri, 2014) : cette dernière présente en effet le même système de quatre petits madriers engagés dans un des murs formé d'une maçonnerie rustique de pierres sèches. Mais dans ce cas précis, ce renfort est manifestement mis en place dès la construction initiale, qui correspond par ailleurs à un bâtiment rural indépendant. Une autre cave, fouillée à SaintApollinaire près de Dijon (Côte-d'Or), montre quant à elle une structure de bois engagée dans chacun des trois grands murs de la pièce, exemple peu commun de cave à armatures, ici attribuable à La Tène finale - époque augustéenne (Videau, 2009).

La petite cave fouillée anciennement aux Damps (Eure), non loin de Val-de-Reuil, fournit également des éléments de comparaison (Halbout-Bertin, 1980, p. 193-195). De plan carré, cette construction enterrée d'environ 2,60 mètres de côté possède des murs en petits moellons calcaires épais de 0,40 mètre. Ces derniers sont percés, au niveau du mur occidental, par deux soupiraux dont l'un était encore équipé d'une grille en fer en forme de croix. À ces ouvertures s'ajoutent, au niveau des murs oriental et septentrional, deux niches rectangulaires. Située à côté de plusieurs bâtiments composant une probable villa, cette cave a été remblayée entre la fin du II $^{\mathrm{e}}$ et le III $^{\mathrm{e}}$ siècle.

Tout naturellement, ces caves rurales offrent un certain nombre de parallèles mais aussi de différences avec celles des villes, ne serait-ce qu'au niveau des techniques de construction. À Rouen, plusieurs caves de tailles et d'élévations variées sont connues. Sans en dresser l'inventaire, on rap- pellera notamment celle découverte place de la Cathédrale et qui est presque carrée $(2,78 \times 2,80 \mathrm{~m}$; Lequoy, Guillot, 2004, p. 130). Accessible par un escalier de huit marches, elle était dotée d'un dallage en pierre et couverte d'une voûte d'arêtes en moellons, ce qui est rare. Une cave beaucoup plus importante $(6 \times 4,25 \mathrm{~m})$ a été mise au jour allée EugèneDelacroix/square Verdrel (Lequoy, Guillot, 2004, p. 133 et fig. 92). Dotée d'un poteau central (en pierre ou en bois?) qui supportait le plafond, elle était construite en petit appareil calcaire et possédait six niches voûtées parfaitement conservées. La fouille menée au début des années 1990 à l'Espace du Palais a quant à elle livré deux caves : l'une (de $9 \mathrm{~m}^{2}$ ) aux murs construits en torchis et colombages et l'autre maçonnée en opus mixtum, associant des niveaux de briques et de moellons calcaires. Cette dernière possédait une seule niche (Lequoy, Guillot, 2004, p. 141, fig. 107-108). Enfin, plus récemment, la fouille menée rue aux Ours a révélé deux intéressantes caves en petit appareil calcaire d'assez grandes dimensions (14 et 17 mètres carrés), dont une à deux soupiraux (Guillot, 2012). Leur principal intérêt réside dans leur construction assez précoce, au plus tard vers le milieu du $\mathrm{I}^{\mathrm{er}}$ siècle, puis leur remblaiement avant la fin de ce siècle.

\section{ConClusion}

Comme leurs consœurs de Gaules romaines, ces quatre caves rurales, pourtant assez modestes, apportent une quantité significative d'informations pour la caractérisation des occupations dont elles font partie, même si ces dernières ne sont que partiellement appréhendées dans le cadre des emprises de fouille. Ceci concerne aussi bien leur emplacement, construction et occupation, que leur comblement et transformation fréquente en dépotoir. Leur comparaison révèle des situations bien différentes dont la plupart sont sans doute à mettre en relation avec le rôle qu'elles occupent au sein des exploitations agricoles concernées. Malgré le manque d'indices tangibles, notamment au niveau des murs ou bien du sol ${ }^{4}$, il est en effet manifeste que leur fonction constitue la raison principale de leur implantation comme de leur mode de construction et de leur distribution. Or, en associant aussi les découvertes plus anciennes, il est remarquable de constater que les caves indépendantes, voire isolées, prédominent largement le petit corpus rural haut-normand, montrant que ces constructions participent plutôt aux activités agricoles et/ou artisanales des domaines, sans relation directe avec le fonctionnement domestique de ce dernier. Cet isolement est toutefois plus ou moins mar-

4. Aucune cave haut-normande n’a pour l'instant révélé de logements à amphores/dolia, comme c'est très souvent le cas dans certaines régions, telle que l'Île-de-France. 
qué, comme le montrent les trois caves de Val-de-Reuil et de Parville. Il est donc possible d'imaginer que les activités pratiquées au sein des constructions, ou bien que la valeur ajoutée des denrées stockées, puissent varier sensiblement, nécessitant de ce fait une proximité plus ou moins étroite avec les espaces cultivés ou bien, au contraire, avec d'autres bâtiments dont elles peuvent être complémentaires. Ce n'est sans doute pas un hasard si la cave de Parville, pourtant indépendante, fait partie du noyau d'habitat tout en étant tournée vers les bâtiments principaux ${ }^{5}$, tandis que celle du Chemin aux Errants à Val-de-Reuil en est nettement détachée. Leur emploi pour le stockage a sans aucun doute été bien différent. Très isolée, celle de Val-de-Reuil, La Cerisaie, apparaît comme un cas un peu particulier qui répond sans doute à un besoin spécifique, bien éloigné d'un lieu de stockage classique, comme l'indique surtout sa cuve maçonnée dont l'installation, pratiquement au milieu de la pièce, démontre l'importance. À l'inverse, la cave d'Isneauville est une composante du bâtiment résidentiel. Est-ce à dire que les denrées entreposées y étaient nettement plus importantes ou plus "sensibles "? Probablement pas, ne serait-ce qu'au regard de la faible ampleur du bâti dans lequel la cave est intégrée et qui peut être mise en rapport avec une occupation particulièrement modeste par sa morphologie et son étendue. Il semble donc que la cave soit ici tout simplement la réserve de la cuisine, tenant alors un rôle essentiellement culinaire. La présence presque certaine de vases de stockage ou bien de rangements (étagères?) le long de l'un des murs ainsi que le mobilier recueilli dans son niveau d'occupation appuient parfaitement cette idée, ne serait-ce que par la quantité importante, véritablement anormale (56\%), de vaisselle fine de table.

Si la date de construction de ces quatre caves est plus ou moins précisée, il apparaît toutefois que trois d'entre elles sont abandonnées puis comblées à peu près à la même période, au $\mathrm{III}^{\mathrm{e}}$ siècle. Leur désaffection marque dans le même temps un abandon complet ou bien une restructuration importante des habitats concernés. Ceci est particulièrement vrai à Val-de-Reuil, La Cerisaie, où le comblement de la cave signe la dernière manifestation humaine de tout le secteur, jusqu'à l'époque contemporaine. À Parville comme à Isneauville, le comblement des caves accompagne l'abandon et la destruction complète des parties résidentielles et bâties, parallèlement au développement d'un nouvel habitat plus simple au cours du Bas-Empire. La plupart des autres caves rurales découvertes dans la région sont dans le même cas et leur comblement est souvent associé au démantèlement, plus ou moins rapide, des exploitations agricoles dont elles

5. Ce qui a engendré l'orientation au nord de cette cave, pour le moins inhabituelle. font partie. Ce phénomène marque simultanément la disparition complète des caves de la culture matérielle régionale pendant de longs siècles, avant leur réintroduction progressive, et surtout exclusive, sur des habitats aristocratiques ou établissements monastiques du Moyen Âge.

\section{Bibliographie}

AdriAn Y.-M. (dir.), 20 I I - Isneauville - Saint-Martin-du-Vivier (76), "ZAC de la Plaine de la Ronce ", Rapport final d'opération de fouille archéologique, (3 volumes), Inrap Grand-Ouest.

Beurion C. (dir.), 2012 - Val-de-Reuil "Le Clos Saint-Cyr, La Cerisaie ", ZAC des Portes (Eure, Haute-Normandie) : une succession d'occupations rurales du Néolithique au Haut-Empire, Rapport de fouille (2 volumes), Inrap Grand-Ouest.

Cliquet D., I993 - Carte archéologique de la Gaule, l'Eure (27), Académie des Inscriptions et Belles-Lettres, ministère de la Culture.

Clotuche R. (dir.), 201 3 - Famars, Parc scientifique du MontHouy (technopôle), Rapport d'étape annuel des fouilles 2011 et 2012, Tranche 1 - phase 1, Inrap Nord-Picardie.

Desfossés Y., I 992 - Épretot, "La Belle au Vent ", Rapport d'évaluation détaillée, A 29, section Le Havre - Yvetot, Afan, SRA de Haute-Normandie.

Ginouves R. et Martin, R., I985-Dictionnaire méthodique de l'architecture grecque et romaine (tome 1), Matériaux, techniques de construction, techniques et formes du décor, École française d'Athènes, Collection de l'École française de Rome $\mathrm{n}^{\circ} 84,310 \mathrm{p}$.

Guillot B. (dir.), 2012 - Rouen, Seine-Maritime, 29-35 rue aux Ours, Rapport de fouille, 2 volumes, Inrap.

Halbout-Bertin D., i 980 - « La fouille de sauvetage de la cave gallo-romaine des Damps (Eure) ", in Le Maнo J. (dir.), Trésors archéologiques de la Haute-Normandie, Rouen, p. 193195.

Hervé-Monteil M.-L, Lukas D., Monteil M. et DietschSellami M.-F., 20 I I - « La viticulture dans l'Ouest de la Gaule Lyonnaise. Les pressoirs de Parville (Eure) et de Piriacsur-Mer (Loire-Atlantique) ", in Poux M., Brun J.-P. et Hervé-Monteil M.-L. (dir.), La vigne et le vin dans les Trois Gaules, Paris, CNRS (Gallia; 68-1), p. 163-214.

Lequor M.-C. et Guillot B., 2004 - Carte archéologique de la Gaule, Rouen 76/2, Académie des Inscriptions et BellesLettres, ministère de l'Éducation nationale, ministère de la Recherche, ministère de la Culture et de la Communication, conseil général de la Seine-Maritime, Maison des Sciences de l'Homme, Paris, 320 p., 322 fig.

LÉOn G. et Adrian Y.-M., I 997 - Eslettes-Fresquiennes " Le Manoir Bosquet ", DFS de fouille, Afan, SRA de Haute-Normandie. 
Lukas D. (dir.), 20 Io - Parville "Bois de Parville " : de la ferme gauloise à la villa gallo-romaine, rapport de fouille, 4 tomes, Inrap Grand-Ouest.

Lukas D. et Lecler-Huby E., 20 io - « L'occupation protohistorique et antique de Parville (27) : les résultats d'une fouille préventive menée au "Bois de Parville " en 2006 ", in ErLenbach F. (dir.), Journées archéologiques de Haute-Normandie, Rouen, 3-5 avril 2009, Publications des universités de Rouen et du Havre, p. 131-138.

Magitteri C. (dir.), 20 I 4 - Dourdan (Essonne) "le Moulin Grouteau - Rue de l'Ermitage - Îlots A2-L2 ", Rapport final d'opération, Inrap Centre Île-de-France.

Poyeton A., avec la collaboration de Auxiette G., Munoz C. et Pissot V., 2003 - L'établissement rural du Bois Rosière à Bessancourt (Val-d'Oise), Diocesis Galliarum, Document de travail no 6, p. 49-76.

Renard-Vignais V. (dir.), I 998 - Grisy-Suisnes, Le Marchais Coubert, La Pièce de Cordon. (RD 471; déviation de Soignolles-
Coubert (77), Document final de synthèse. (2 vol.). Afan, SRA d'Île-de-France.

SÉRIs D. (dir.), 2009 - Jard-sur-Mer "Le grand Essart " - Une villa gallo-romaine et une occupation de l'Antiquité tardive et du Haut Moyen Âge, Rapport final d'opération de fouille, 2 volumes, Inrap Grand-Ouest.

Videau G. (dir.), 2009 - Saint-Apollinaire, Pré Thomas (Côte-d'Or, 21). Une occupation diachronique : des vestiges de l'âge du Bronze à un établissement rural aux confins de La Tène finale et de la période augustéenne, Rapport final d'opération, Inrap GrandEst Sud.

Wabant M., Abert F. et Vermeersch D., 2006 - Carte archéologique de la Gaule, Le Val-d'Oise (95), Académie des Inscriptions et Belles-Lettres, ministère de la Culture et de la Communication, conseil général du Val-d'Oise, 495 p. et 497 fig.

Zusammenfassung: Die gallo-römischen Keller in den ländlichen Siedlungen der Haute-Normandie - Die jüngst erfolgte archäologische Untersuchung von vier römischen Kellern in der Haute-Normandie hat es ermöglicht, diese in die Erde eingetieften Befunde gemeinsam und vergleichend zu studieren. Ausgehend von ihrer verschiedenen Architektur sowie von ihrer unterschiedlichen Lage liefern diese Befunde bemerkenswerte Informationen zu den Auftraggebern dieser Bauten wie auch zu ihren Erbauern. Darüber hinaus stellt sich naturgemäß die Frage nach ihrer Funktion, selbst wenn diese in den meisten Fällen aufgrund der fehlenden archäologischen Hinweise nur schwer zu beantworten ist. Die Kellerverfüllungen liefern in der Regel wichtige Informationen, um die jeweilige Besiedlung näher zu charakterisieren.

Resumen: Las cuevas galo-romanas en los campos de Haute-Normandie - La reciente excavación de cuatro cuevas antiguas en Alta-Normandia ofrece la oportunidad de un enfoque conjunto y comparativo de estas cámaras subterráneas. A través de su variedad arquitectural y de sus distintas ubicaciones, estas bodegas ofrecen una gran cantidad de informaciones sobre los deseos de los patrocinadores y de los constructores. Más allá, se trata obviamente de clarificar sus papeles, aunque sea difícil de especificar, por falta de pruebas. Sin embargo, no hay que minimizar la importancia de los rellenos que sirven para caracterizar las ocupaciones asociadas.

Schlüsselwörter: Keller, Römische Zeit, Haute-Normandie, ländliche Besiedlung, Architektur.

Palabras clave: cueva, antiguedad, Alta-Normandia, medio rural, arquitectura. 